\title{
AFNP - ANÁLISE FUNCIONAL DOS NERVOS PERIFÉRICOS DESENVOLVIMENTO DE UM SOFTWARE FLEXÍVEL NO ESTUDO DE REGENERAÇÃO NERVOSA PERIFÉRICA
}

\section{ALEXANDRE CALURA YAMASITA}

Dissertação de mestrado apresentada ao Programa de Pós-Graduação Interunidades em Bioengenharia - Escola de Engenharia de São Carlos / Faculdade de Medicina de Ribeirão Preto / Instituto de Química de São Carlos da Universidade de São Paulo como parte dos requisitos para a obtenção do título de mestre em Bioengenharia.

Área de Concentração: Bioengenharia

Orientador: Prof. Dr. Nilton Mazzer

São Carlos 


\begin{abstract}
AUTORIZO A REPRODUÇÃO E DIVULGAÇÃO TOTAL OU PARCIAL DESTE TRABALHO, POR QUALQUER MEIO CONVENCIONAL OU ELETRÔNICO, PARA FINS DE ESTUDO E PESQUISA, DESDE QUE CITADA A FONTE.
\end{abstract}

Ficha catalográfica preparada pela Seção de Tratamento da Informação do Serviço de Biblioteca - EESC/USP

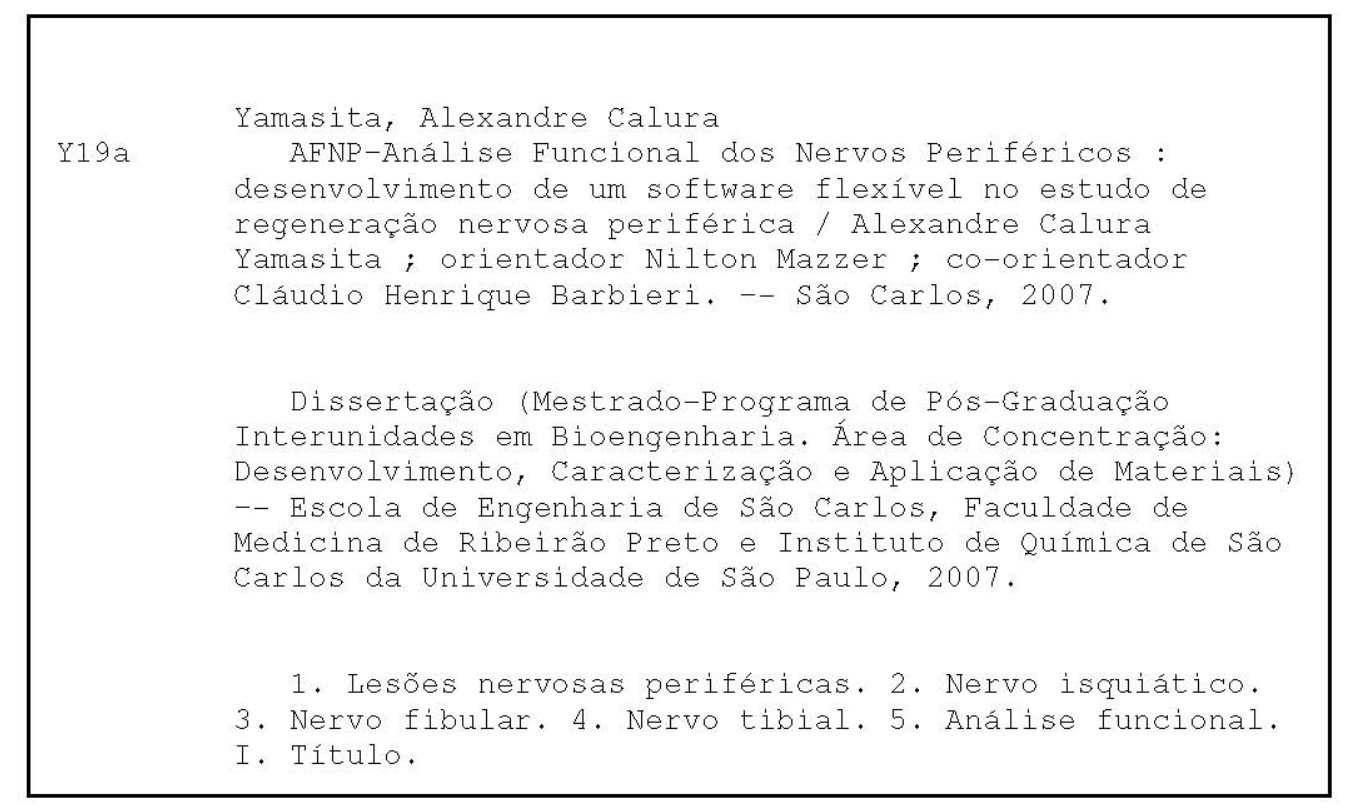


"Just as banks cannot practice modern banking without financial software, and airlines cannot manage modern travel planning without shared databanks of flight schedules and reservations, it is increasingly difficult to practice modern medicine without information technologies."

Edward H. Shortliffe \& Leslie E. Perreault 


\section{Agradecimentos}

Ao Prof. Dr. Nilton Mazzer, pela pronta orientação neste trabalho.

Ao Prof. Dr. Cláudio Henrique Barbieri, pelas criteriosas revisões.

À minha querida família, pelo apoio em toda a minha vida.

À minha esposa, Lidiane Silva de Matos Yamasita.

À Smar Equipamentos Industriais Ltda., empresa na qual trabalhei durante o período em que conduzi este trabalho. 


\section{RESUMO}

YAMASITA, A.C.(2007). AFNP - análise funcional dos nervos periféricos: desenvolvimento de um software flexível no estudo da recuperação de lesões nervosas periféricas. 48 f. Dissertação (Mestrado) - Programa de Pós-graduação da Interunidades em Bioengenharia (EESC/FMRP/IQSC), Universidade de São Paulo, São Carlos, 2007.

O estudo da recuperação de lesões nervosas periféricas do isquiático, fibular e tibial, com base nos métodos (De Medinaceli; Freed; Wyatt, 1982), (De Medinaceli; Derenzo; Hunter, 1984), (Carlton; Goldberg, 1986) e (Bain; Mackinnon; Hunter, 1989), obtidos por meio da análise motora, é considerado um bom critério de avaliação para a quantificação do grau de avaliação nervosa. Elas podem ser estudadas através de uma ampla variedade de técnicas que incluem a eletrofisiologia muscular e a morfologia. Porém nem mesmo em condições experimentais controladas, uma correlação da regeneração dos nervos periféricos é completa, porque não provêem informações precisas do estado funcional do nervo. A avaliação da função sensorial é imprecisa e usualmente indireta devido a causas de enervações sobrepostas. Sendo assim, há explicação para os diferentes métodos de avaliação funcional propostos com os avanços tecnológicos, e o aprimoramento dos métodos de captação, armazenamento e processamento dos dados obtidos. O sistema de Análise Funcional dos Nervos Periféricos - AFNP, nome dado ao software devido a sua funcionalidade que é de análise funcional de nervos periféricos, apresenta uma interface de fácil interação, emprego e de apresentação das informações ao usuário, através de auxílio de informações de cada contexto do sistema de como utilizá-lo. Sua precisão e a uniformidade das avaliações proporcionaram resultados confiáveis. O uso de recursos gráficos e de relatórios pode disponibilizar os resultados obtidos, por meio de gráficos das médias e de desvios-padrão. A informatização deste processo, além de fornecer ao usuário uma maior agilidade na avaliação, permite ao pesquisador a utilização de um número maior de animais nos grupos experimentais, facilitando não só a captação, bem como o armazenamento e o processamento dos dados. A flexibilidade foi um resultado muito importante a ser ressaltado, pois mais de um usuário tem a possibilidade de interagir no sistema.

Palavras-chave: Lesões nervosas. Periféricas. Isquiático. Fibular. Tibial. Análise

funcional. 


\section{ABSTRACT}

YAMASITA, A.C. (2007). AFNP - functional analysis of the peripheral nerves: development of a flexible software in the study of the recovery of nervous lesions peripherals. 48 f. Dissertação (Mestrado) - Programa de Pós-graduação da Interunidades em Bioengenharia (EESC/FMRP/IQSC), Universidade de São Paulo, São Carlos, 2007.

The study of the nervous recuperation of peripheral lesions of the sciatic, fibular and tibial, with base in the methods of (De Medinaceli; Freed; Wyatt, 1982), (De Medinaceli; Derenzo; Hunter, 1984), (Carlton; Goldberg, 1986) and (Bain; Mackinnon; Hunter, 1989), obtained through the motive analysis, is considered a good evaluation criterion for the quantification of the degree of nervous evaluation. They can be studied through a wide variety of techniques including the muscular electrophysiology and the morphology. However not even in controlled experimental conditions, a correlation of the regeneration of the peripheral nerves is complete, because they don't provide necessary information of the functional state of the nerve. The evaluation of the sensorial function is imprecise and usually indirect due to causes of overlap enervations. Being like this, the explanation for the different functional evaluation methods proposed with the technological progresses and the improvement of the reception methods, storage and processing of the obtained data. The system of Functional Analysis of the Peripheral Nerves - AFNP, name given to the software due to its functionality that is of functional analysis of outlying nerves, it presents an interface of easy interaction, work and of presentation of the information to the user, through help information of each context of the system of how to use it. Its precision and the uniformity of the evaluations provided reliable results. The use of graphic resources and reports they can make available the obtained results, through graphs of the averages and of deviations pattern. With the computerization of this process, besides supplying the user a larger agility in the evaluation, it provides the researcher the use of a larger number of animals in the experimental groups, facilitating not only the reception, as well as the storage and the processing of the data. The flexibility was a very important result to be stood out, therefore more than one user has the possibility to interact with the system.

Key words: Lesions nervous. Peripheral. Sciatic. Fibular. Tibial. Functional analysis. 


\section{LISTA DE FIGURAS}

Figura 1: Medição das pegadas obtidas por De Medinaceli, Freed e Wyatt (1982) ........16

Figura 2:Mesa digitalizadora por De Medinaceli, Derenzo E Wyatt............................. 19

Figura 3: Procedimento experimental de Bain, Mackinnon e Hunter (1989)................. 25

Figura 4: Comparação entre os métodos de registro de marcha. À direita o registro utilizando filmes de raios $\mathrm{X}$, e à esquerda o registro utilizando método de Lowdon, Seader e Urbaniak (1988). 33

Figura 5: Registro obtido da trilha,segundo o método de Lowdon, Seader e Urbaniak

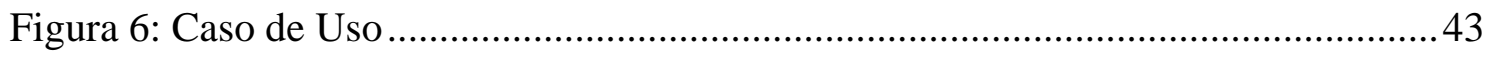

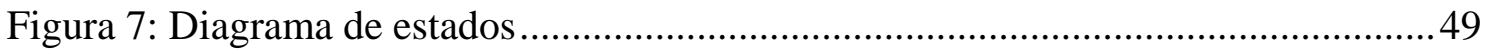

Figura 8: Ciclo de vida do desenvolvimento iterativo e incremental............................50

Figura 9: Visualização do Banco de Dados ................................................................56

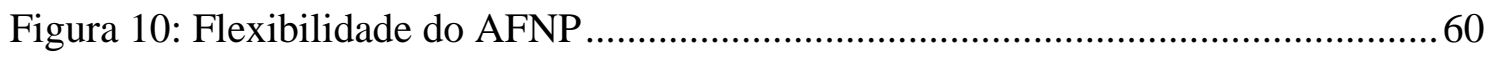

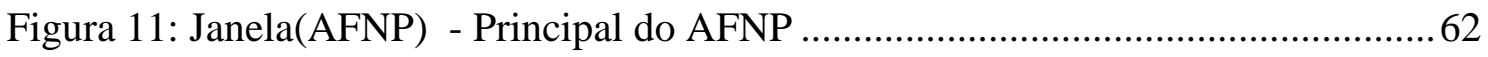

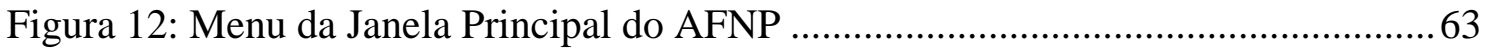

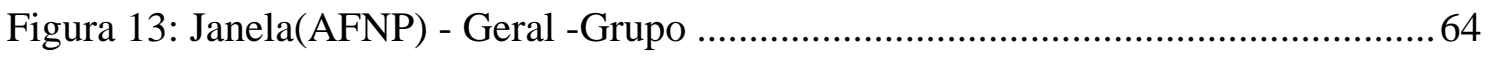

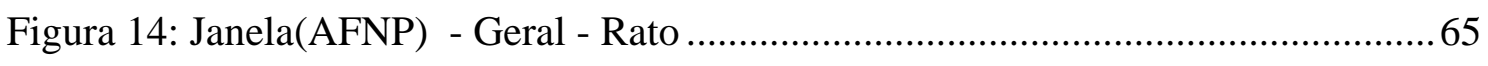

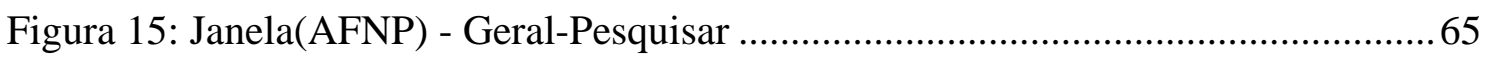

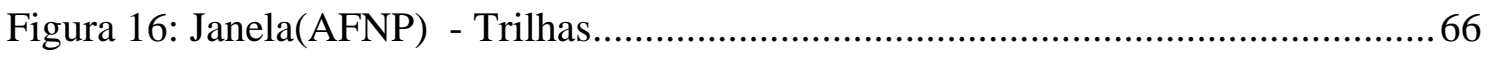

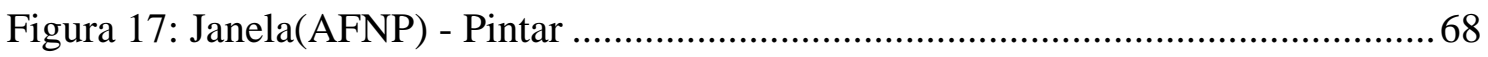

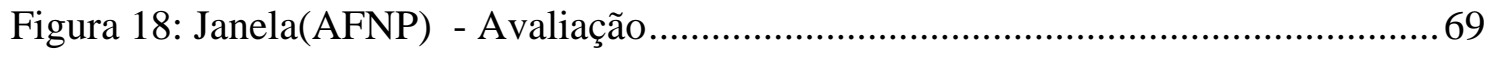

Figura 19: Janela(AFNP) - Configuração de Gráfico ................................................ 70 


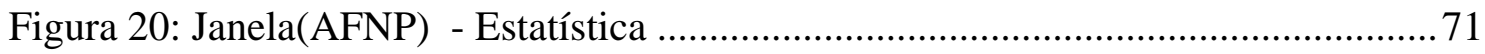

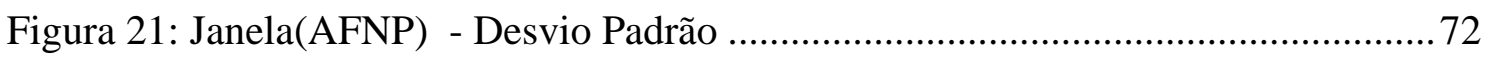

Figura 22: Janela(AFNP) - Aba Pesquisar-Histórico................................................ 73

Figura 23: Janela(AFNP) - Aba Gráfico-Histórico ....................................................... 74

Figura 24: Janela(AFNP) - Geração de Registro ......................................................... 75

Figura 25: Programa Geração de Registro ................................................................ 76

Figura 26: Janela(AFNP) - Chave de Registro ....................................................... 77

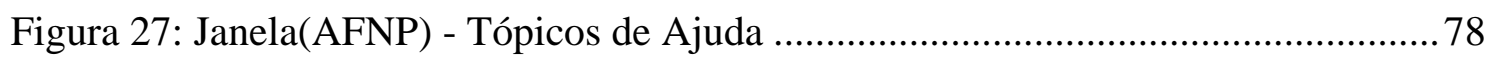

Figura 28: Janela(AFNP) - Botão de Ajuda Sensível ao Contexto................................ 79

Figura 29: Janela(AFNP) - Ajuda Sensível ao Contexto ............................................ 79

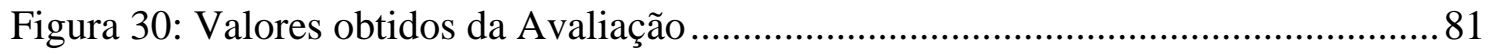

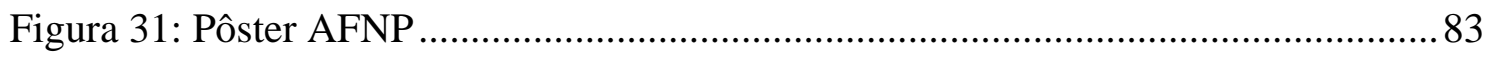




\section{LISTA DE GRÁFICOS}

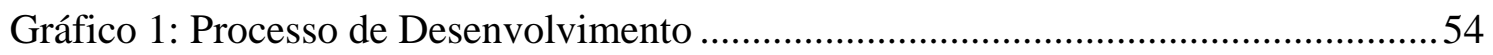

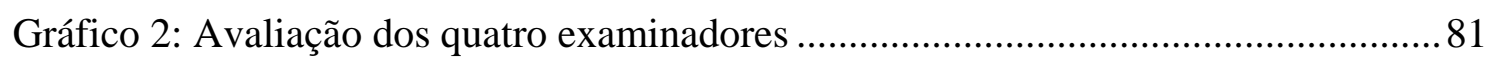

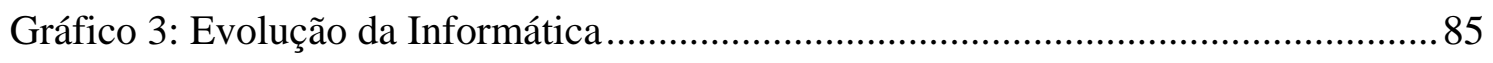




\section{LISTA DE TABELAS}

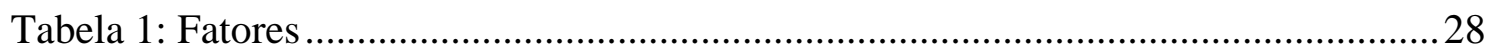

Tabela 2:Correlação dos Métodos de Registro de Marcha ...........................................32 


\section{LISTA DE ABREVIATURAS E SIGLAS}

AFNP - Avaliação Funcional de Nervos Periféricos

DBMS - Sistema de Gerenciamento de Banco de Dados

SFI - Índice Funcional do Isquiático

PFI - Índice Funcional Fibular

TFI - Índice Funcional Tibial

SIMMS - Sistema de Gerenciamento do Índice do Isquiático, por De Medinaceli (1984)

NTOF - Distância Normal ao Pé Oposto

ETOF - Distância Experimental ao Pé Oposto

NPL - Comprimento Normal da Pegada

EPL - Comprimento Experimental da Pegada

NTS - Distância Normal do Primeiro ao Quinto Dedo

ETS - Distância Experimental do Primeiro ao Quinto Dedo

NIS - Distância Normal do Segundo ao Quarto Dedo

EIS - Distância Experimental do Segundo ao Quarto Dedo

RUP - Processo Unificado da Rational

UML - Linguagem de Modelagem Unificada

CIS-EPM - Centro de Informática em Saúde - Escola Paulista de Medicina 
UNIFESP/EPM - Universidade Federal de São Paulo - Escola Paulista de Medicina 


\section{RESUMO}

ABSTRACT

LISTA DE FIGURAS

LISTA DE GRÁFICOS

LISTA DE TABELAS

\section{LISTA DE SIGLAS E ABREVIATURAS}

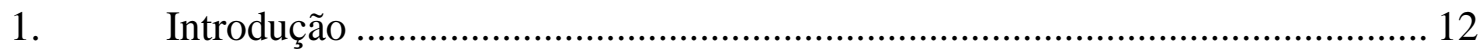

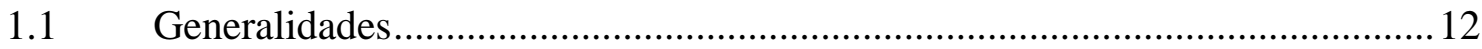

1.2 Avaliação em Modelo Experimental ............................................................. 14

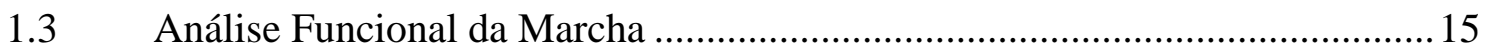

1.3.1 Método de De Medinaceli, Derenzo e Wyatt (1984) .........................................17

1.3.2 Método de Carlton e Goldberg (1986) ............................................................20

1.3.3 Método de Bain, Mackinnon e Hunter (1989) .................................................25

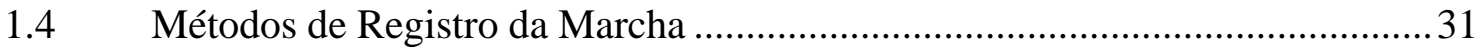

1.4.1 Utilização de Filmes de Raios X..................................................................... 31

1.4.2 Utilização de Papel Azul de Bromofenol............................................................ 31

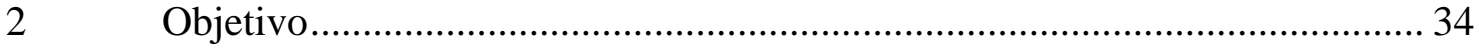

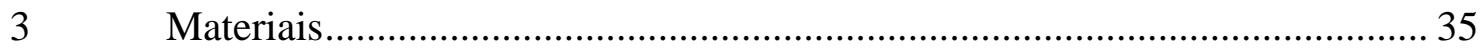

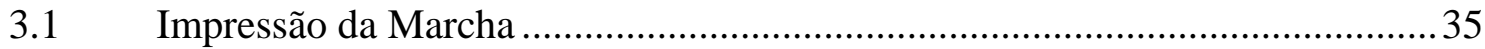

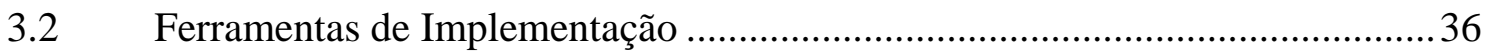

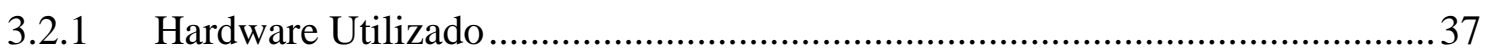

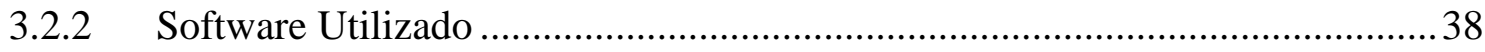

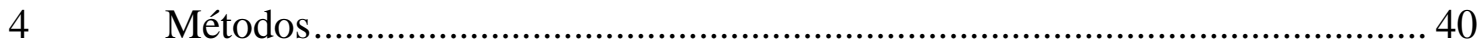

4.1 Linguagem Modelagem Unificada - UML ................................................ 40

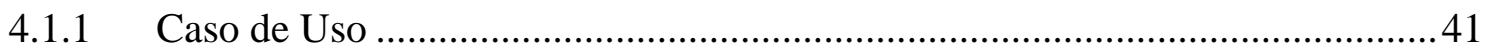

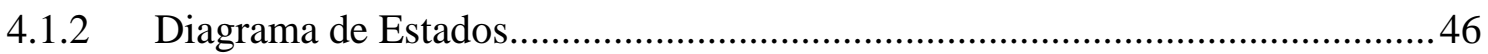

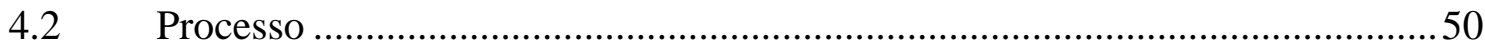




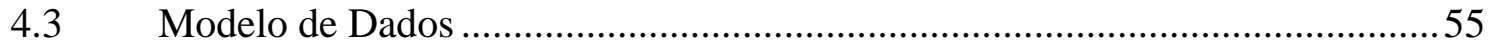

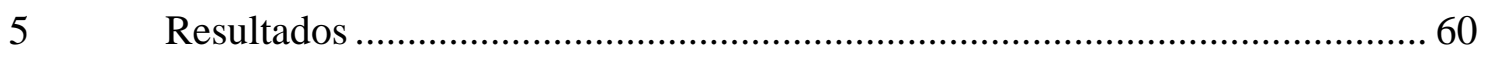

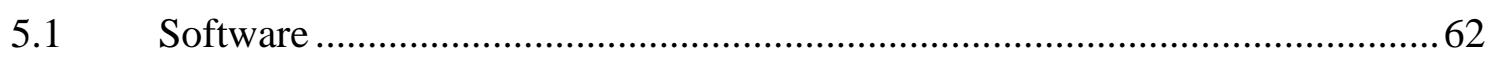

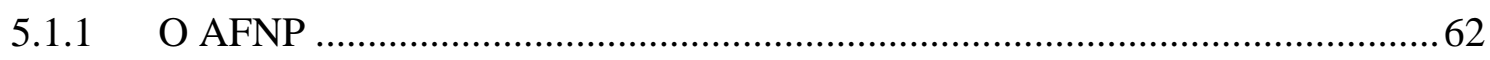

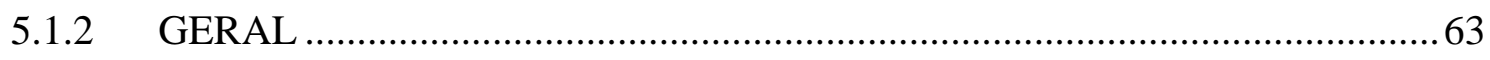

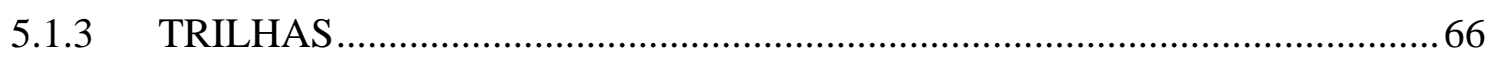

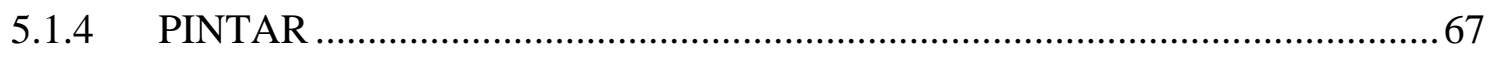

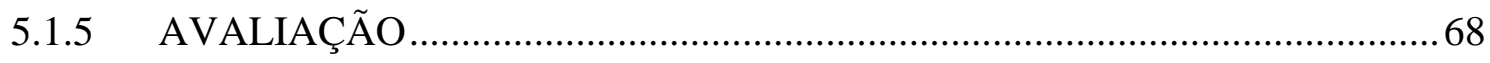

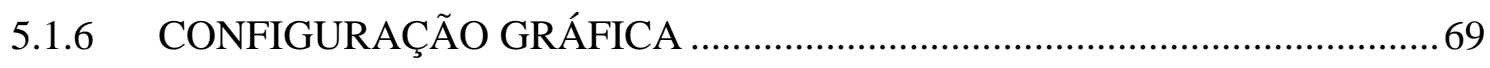

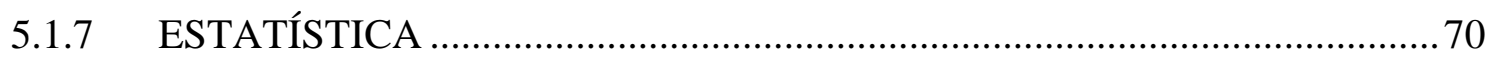

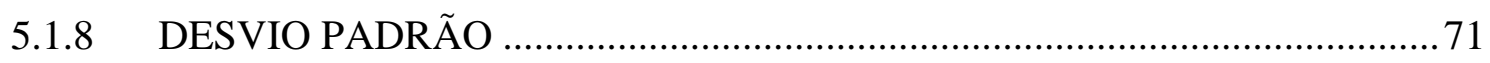

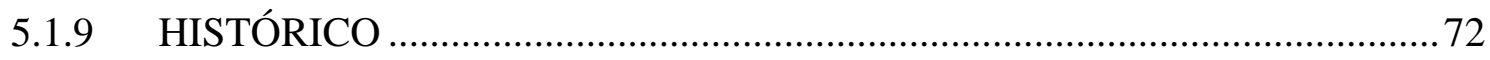

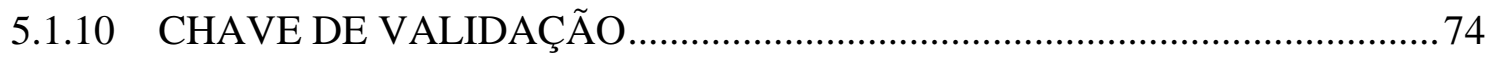

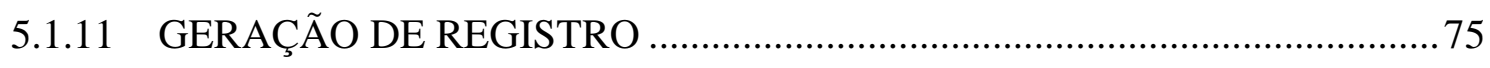

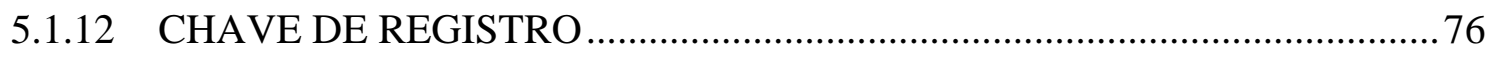

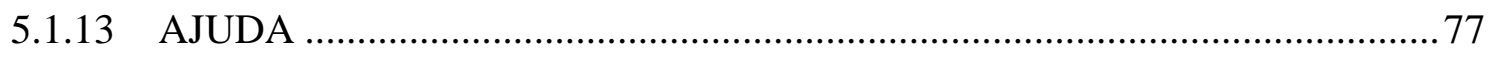

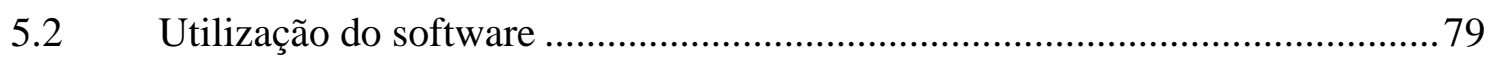

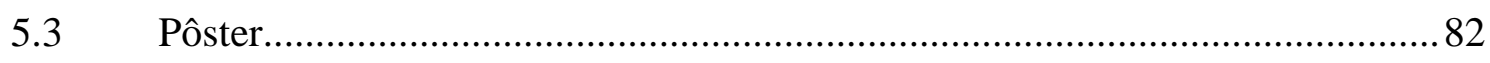

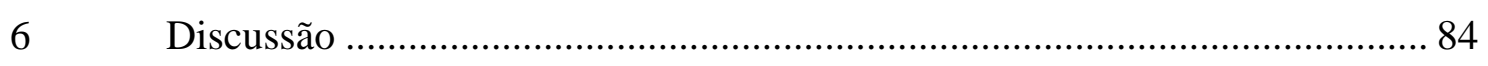

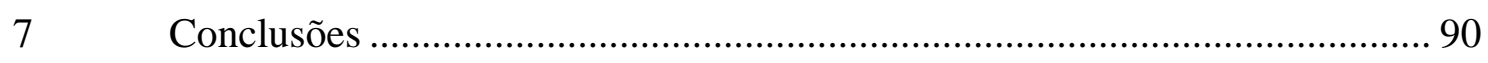

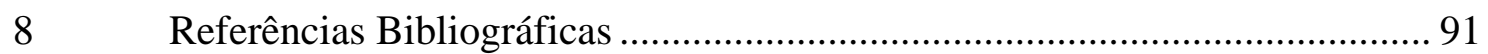




\section{Introdução}

\subsection{Generalidades}

Desde os primórdios da informática houve entusiasmo no sentido de usar o computador como ferramenta de auxílio no diagnóstico médico. Assim em 1959, Ledley e Lusted descreveram a utilização da lógica simbólica e da estatística como métodos para auxiliar o processo de decisão e apontaram o computador como o instrumento adequado para auxiliar o processo de diagnóstico.

O processo de diagnóstico médico depende basicamente da qualidade da informação coletada do paciente e do conhecimento da área em apreço. No que diz respeito à coleta de dados, é necessário ter um número suficiente e conter os tópicos de maior relevância para a identificação do diagnóstico e o subseqüente planejamento terapêutico.

A primeira aplicação prática da computação relevante para a área da saúde foi o desenvolvimento de um sistema de processamento de dados baseado em cartões perfurados, criado por Herman Hollerith em 1890. Primeiramente utilizado para a realização do censo dos Estados Unidos daquele ano, o sistema foi, logo a seguir, adotado para solucionar problemas nas áreas de epidemiologia e saúde pública (BLOIS; SHORTLIFFE, 1990). 
Especificamente, o escopo do estudo deste trabalho é a manipulação da informação pela quantificação funcional através de avaliações morfológicas e eletrofisiológicas em meios computacionais, por meio da análise da marcha, com os nervos isquiático, tibial e fibular, utilizando os métodos De Medinaceli, Carlton e Goldberg e Mackinnon.

O nervo isquiático de diferentes animais tem sido usado em estudos e pesquisas sobre regeneração de nervos periféricos. Lesões no tronco do nervo, seguidas de diversas formas de tratamento e submetidas a diferentes técnicas de avaliação funcional do membro, têm sido um dos focos de pesquisas sobre a regeneração do nervo isquiático, em particular, e dos nervos periféricos, em geral.

A análise da marcha, realizada durante o curso do estudo da avaliação, fornece ao pesquisador a oportunidade única de avaliar aspectos específicos de recuperação nervosa em um modelo não hostil. A exatidão do índice funcional realizado em lesões nervosas ou estudos regenerativos pode ser confirmada com o uso de grupos, constituídos com elementos (ratos). Os nervos periféricos dos ratos são semelhantes aos dos tecidos humanos. Além disso, o animal é barato e fácil de trabalhar e já muito bem estudado pelos pesquisadores (MACKINNON, 1989). A primeira análise é feita com o animal em estado normal ou também chamado estado de controle. Depois, os ratos do grupo são lesados e analisados, conforme o método em relação ao fator tempo. Isto permite ao investigador acompanhar a evolução da recuperação do nervo lesado, mas também auxiliá-lo na determinação de uma ótima avaliação da regeneração elétrica e histológica. Este estado é chamado de experimental. 


\subsection{Avaliação em Modelo Experimental}

As técnicas de avaliação funcional do nervo isquiático, com métodos baseados em morfologia e eletrofisiologia, têm sido questionadas através dos tempos, devido à baixa correlação entre os resultados obtidos e a resposta funcional do membro, como enfatizado por (De Medinaceli; Freed; Wyatt, 1982), (De Medinaceli; Derenzo; Wyatt, 1984), (Carlton; Goldberg, 1986) e (Bain; Mackinnon; Hunter, 1989).

Entretanto, numa lesão de um nervo periférico, inúmeras alterações musculares e nervosas ocorrem. Sua regeneração raramente é completa e perfeita, apesar das técnicas sofisticadas de reconstrução (MENDONÇA, 2000).

A natureza, o nível da lesão, período de denervação, tipo, função e diâmetro da fibra nervosa são fatores que podem determinar as diferentes velocidades de regeneração. Outros fatores podem interferir como a idade do paciente, a variação de agentes químicos e temperatura (SUNDERLAND, 1985).

No caso das análises eletromiográficas, adquiridas por meio de eletrodo e apresentadas por computadores ou osciloscópios de raios catódicos, não traz resultados conclusivos, o que decorre, em parte, da baixa relação sinal/ruído do sinal elétrico adquirido (OLIVEIRA, 2001).

Neste contexto, surgiram diversos trabalhos e publicações sobre avaliações funcionais baseadas na análise da marcha, com o modelo experimental em ratos. 


\subsection{Análise Funcional da Marcha}

(De Medinaceli; Freed; Wyatt, 1982) descreveram a primeira equação para análise funcional da regeneração do nervo isquiático em ratos. A equação foi gerada dentre as medidas de determinados parâmetros nas pegadas normais e de medidas equivalentes nas pegadas ditas experimentais obtidas (com lesão do nervo isquiático), obtidas fazendo os animais caminharem sobre filmes de raios $\mathrm{X}$ expostos com as patas molhadas em solução reveladora (Figura 1). 


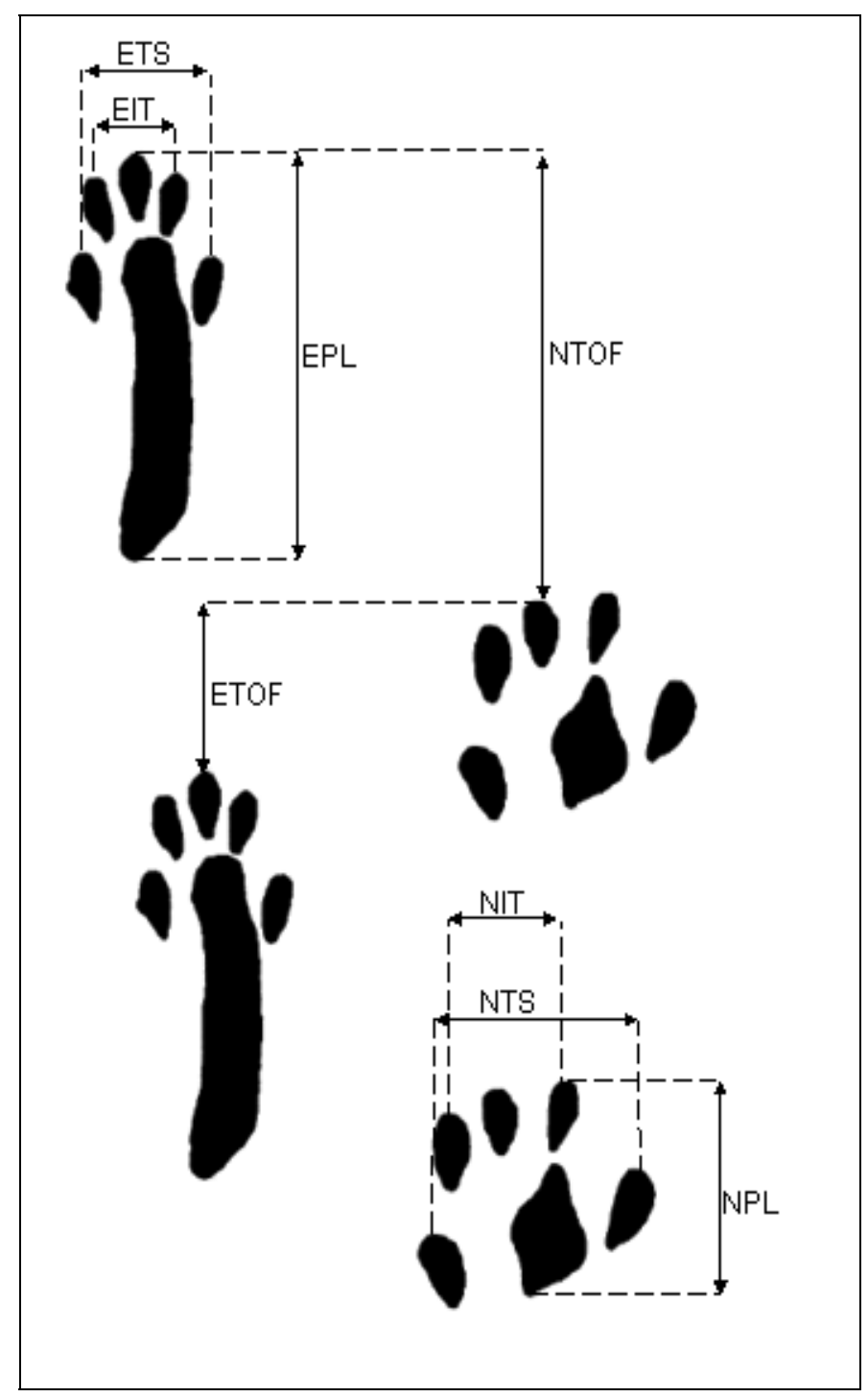

Figura 1: Medição das pegadas obtidas por De Medinaceli, Freed e Wyatt (1982)

A equação foi derivada empiricamente, atribuindo um peso igual às variáveis medidas e empregando um fator de ajuste $(2,2)$, como se segue:

$S F I=\left[\left(\frac{E T O F-N T O F}{N T O F}\right)+\left(\frac{N P L-E P L}{E P L}\right)+\left(\frac{E T S-N T S}{N T S}\right)+\left(\frac{E I S-N I S}{N I S}\right)\right] \times 2.2 \times \frac{100}{4}$

onde: ETOF: Experimental to other foot 
NTOF: Normal to other foot

NPL: Normal print length

EPL: Experimental print length

ETS: Experimental toe spread

NTS: Normal toe spread

EIS: Experimental intermediary toe spread

NIS: Normal intermediate toe spread

Essa equação foi chamada de Índice Funcional do Isquiático (SFI, ou Sciatic Functional Index), seu resultado variando de - 100\%, que significa disfunção completa, a $0 \%$, que significa normalidade.

\subsubsection{Método de De Medinaceli, Derenzo e Wyatt (1984)}

Posteriormente, (De Medinaceli; Derenzo; Wyatt, 1984) descreveram o primeiro método computadorizado de avaliação do índice funcional do isquiático, o Sistema de Manuseio do Índice Ciático (SIMMS - Sciatic Index Management System). Utilizaram para isso de uma combinação complexa e de custo elevado de equipamentos, que incluíam um computador de grande porte (Mainframe), estações com terminais gráficos para análise, um terminal serial tipo PT 100, uma mesa digitalizadora, um 
sistema de manuseio de base de dados (DBMS, database management system) e pacotes estatísticos. Nesse experimento, sete ratos da espécie Sprague-Dawley foram anestesiados, o tronco do nervo isquiático esquerdo foi esmagado com uma pinça de extremidades serrilhadas por 1 minuto, de forma a aplicar uma força constante de compressão na área de secção transversal. A ferida operatória era fechada em seguida e o animal foi posto em observação por um período de 53 dias, durante o qual eram obtidos registros da sua marcha. Era sabido que esse tipo de ferimento no tronco do nervo provocaria uma total paralisia motora e sensitiva do membro, mas que após algumas semanas o nervo recuperaria suas funções normais, com a regeneração das suas fibras. Os registros da marcha foram obtidos já no pré-operatório e, depois, a intervalos regulares, em tiras de filme de raios $\mathrm{X}$ do mesmo modo que no experimento anterior (De Medinaceli; Freed; Wyatt, 1982).

O uso do SIMMS foi feito na seguinte seqüência:

1. aquisição das medidas das variáveis em mesa digitalizadora e em terminal gráfico colorido (figura 2);

2. transferência dos dados ao mainframe;

3. manipulação dos dados no DBMS, portanto no mainframe, por meio de um terminal tipo caractere PT-100;

4. geração de arquivos de dados para tratamento com outros pacotes estatísticos;

5. geração de relatórios. 
Para avaliação do método, os cálculos do SFI (Índice Funcional do Ciático) foram feitos por dois observadores independentes, em três eventos diferentes:

1.Cálculos efetuados à mão por observador principal

2.Cálculos efetuados no SIMMS por observador principal;

3.Cálculos efetuados no SIMMS por observador não treinado.

Os resultados da comparação e correlação entre classes foram considerados excelentes, com exceção do quarto dia pós-operatório, devido às dificuldades do animal em efetuar as primeiras caminhadas.

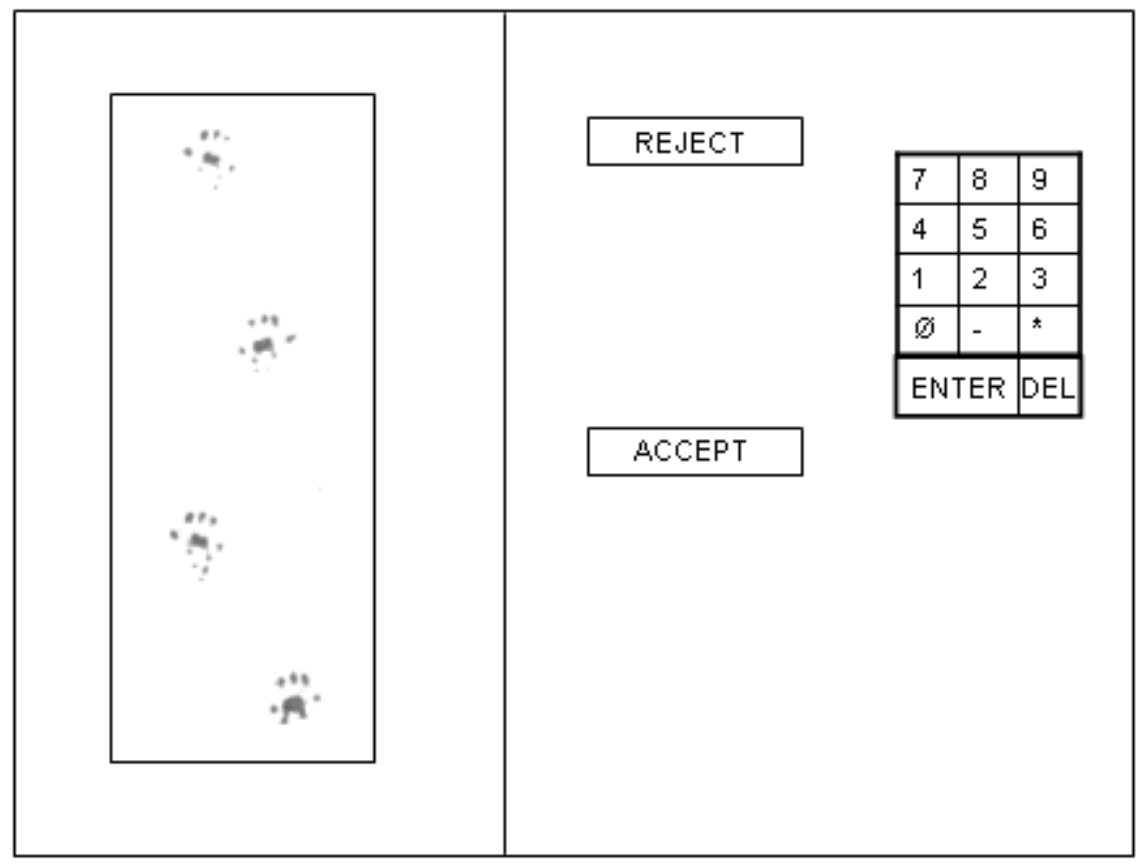

Figura 2:Mesa digitalizadora por De Medinaceli, Derenzo E Wyatt 
A implementação do método SIMMS, segundo (De Medinaceli; Derenzo; Wyatt, 1984), trouxe alguns benefícios à avaliação da função nesses casos, como a diminuição do tempo de avaliação, o aumento da precisão e a uniformidade do método, vantagens que viriam a aumentar a produtividade de seu centro de pesquisas, habilitando os pesquisadores a obterem avaliações mais fáceis e rápidas do SFI.

\subsubsection{Método de Carlton e Goldberg (1986)}

(Carlton; Goldberg, 1986), utilizando uma modificação do método de (De Medinaceli; Derenzo; Wyatt, 1984) para avaliação do SFI, desenvolveram um método próprio com a finalidade de avaliar a função do ciático, retirada do fator de distância ao outro pé (TOF - to other foot) e ajuste na constante de peso. Os índices dos nervos fibular e tibial (PFI e TFI) foram desenvolvidos usando análises regressivas lineares de múltiplas variáveis.

As fórmulas usadas foram as seguintes:

$$
S F I=\left[\left(\frac{N P L-E P L}{E P L}\right)+\left(\frac{E T S-N T S}{N T S}\right)+\left(\frac{E I S-N I S}{N I S}\right)\right] \times 73
$$


$T F I=125 \times\left(\frac{N P L-E P L}{E P L}\right)-43.8 \times\left(\frac{E T S-N T S}{N T S}\right)+252 \times\left(\frac{E I S-N I S}{N I S}\right)$

$P F I=2 \times S F I-T F I$

Assim, operaram 18 ratos Wistar, com peso médio de 200 g, distribuídos em quatro grupos experimentais, como se segue:

1. Lesão do componente tibial;

2. Lesão do componente fibular;

3. Lesão de todo o nervo isquiático;

4. Controle (sham operation).

As lesões, análogas para cada grupo, foram o esmagamento num local situado a dez milímetros(10mm) aproximadamente da fossa poplítea da perna esquerda. No quarto grupo, de controle, foi realizada apenas a dissecção fascicular, sem esmagamento de nervo. Impressões da marcha, registradas em filme de raios $\mathrm{X}$, foram obtidas semanalmente por um período de cinco semanas. 
Onde:

SFI: Índice Funcional do Isquiático

TFI: Índice Funcional do Tibial

PFI: Índice Funcional do Fibular

As demais siglas são as mesmas que para a equação de (De Medinaceli; Derenzo; Wyatt, 1984).

Como resultado da aplicação das suas equações, (Carlton; Goldberg, 1986) obtiveram, em cinco semanas de avaliação, os seguintes resultados:

$\checkmark$ Grupo de Controle

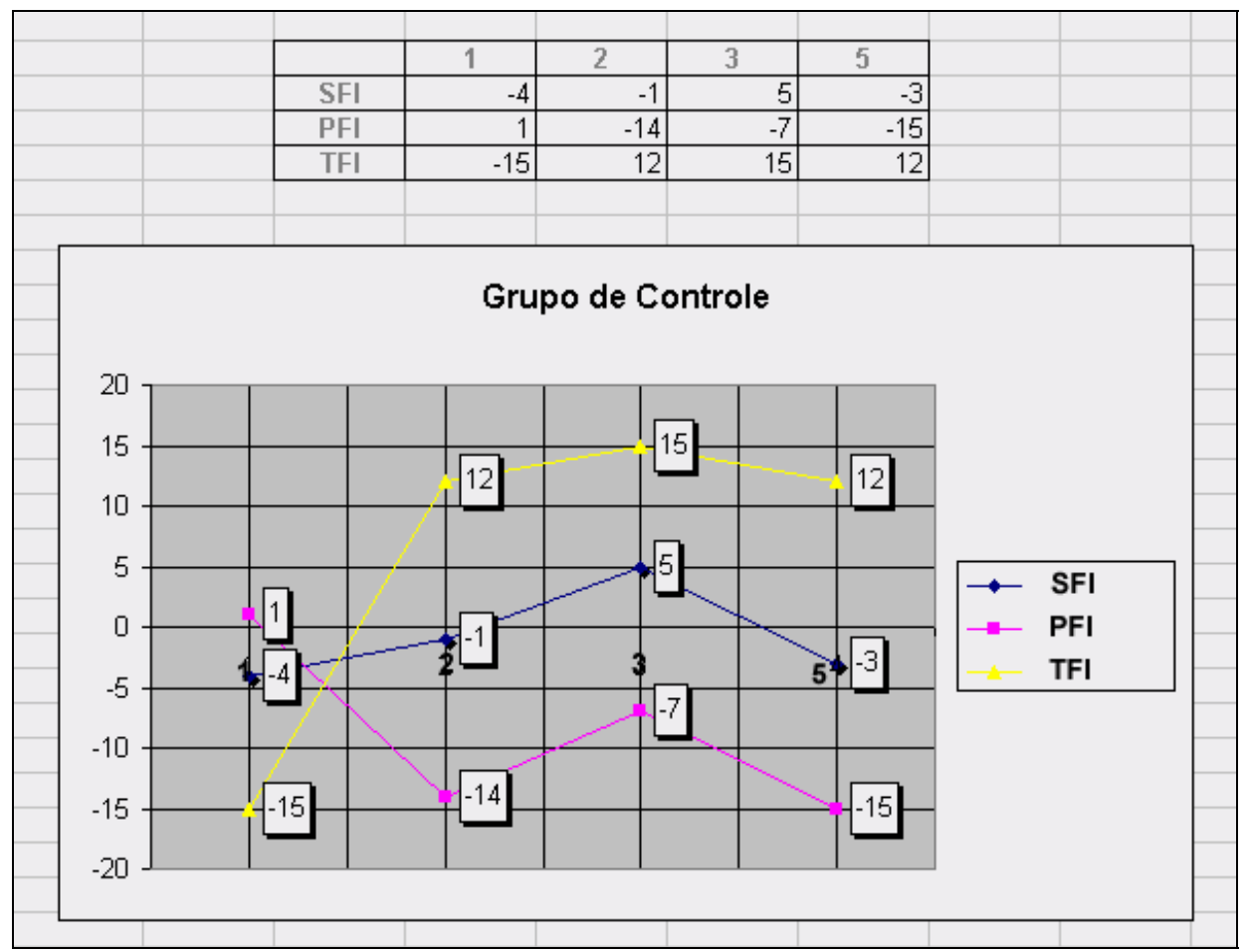


$\checkmark$ Esmagamento do Fibular

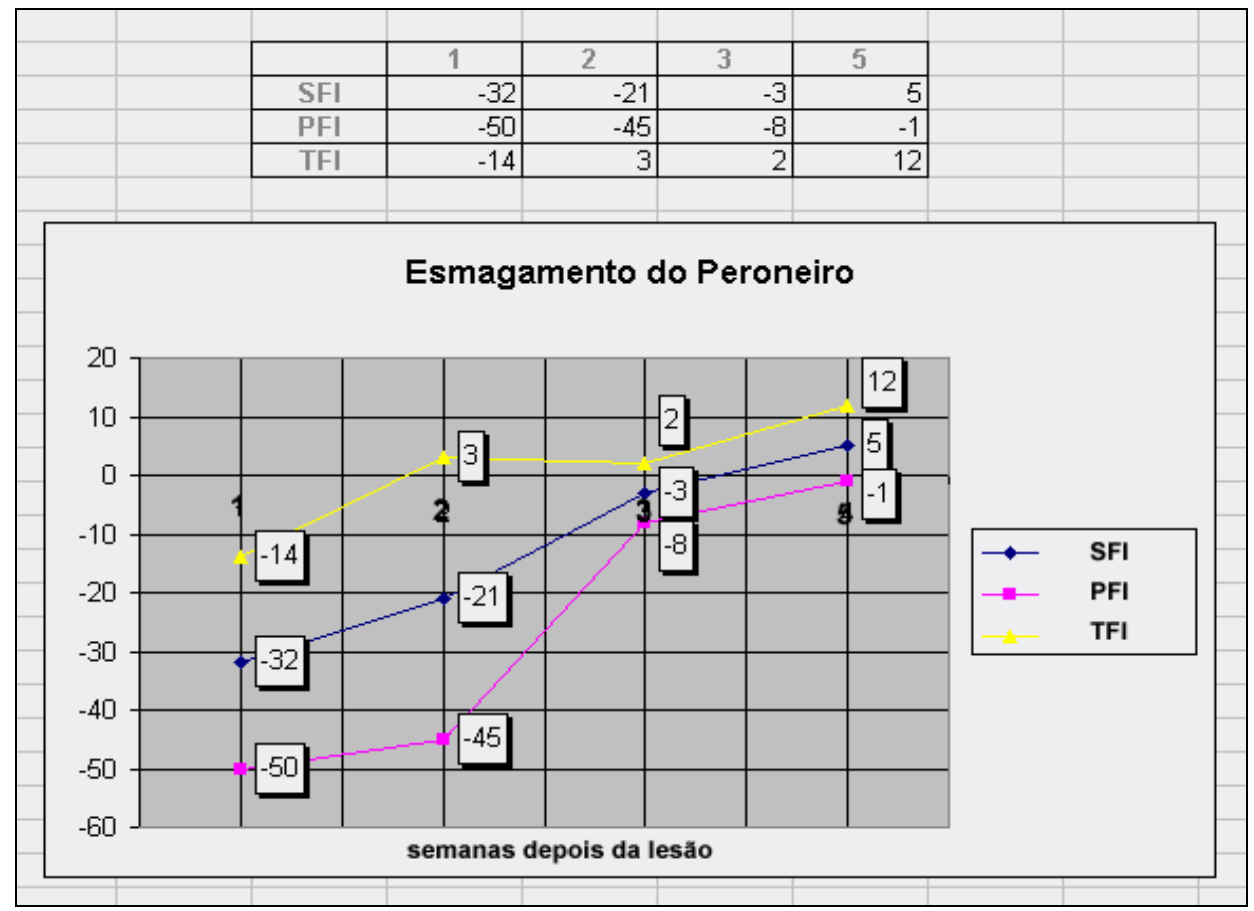


$\checkmark$ Esmagamento do Tibial

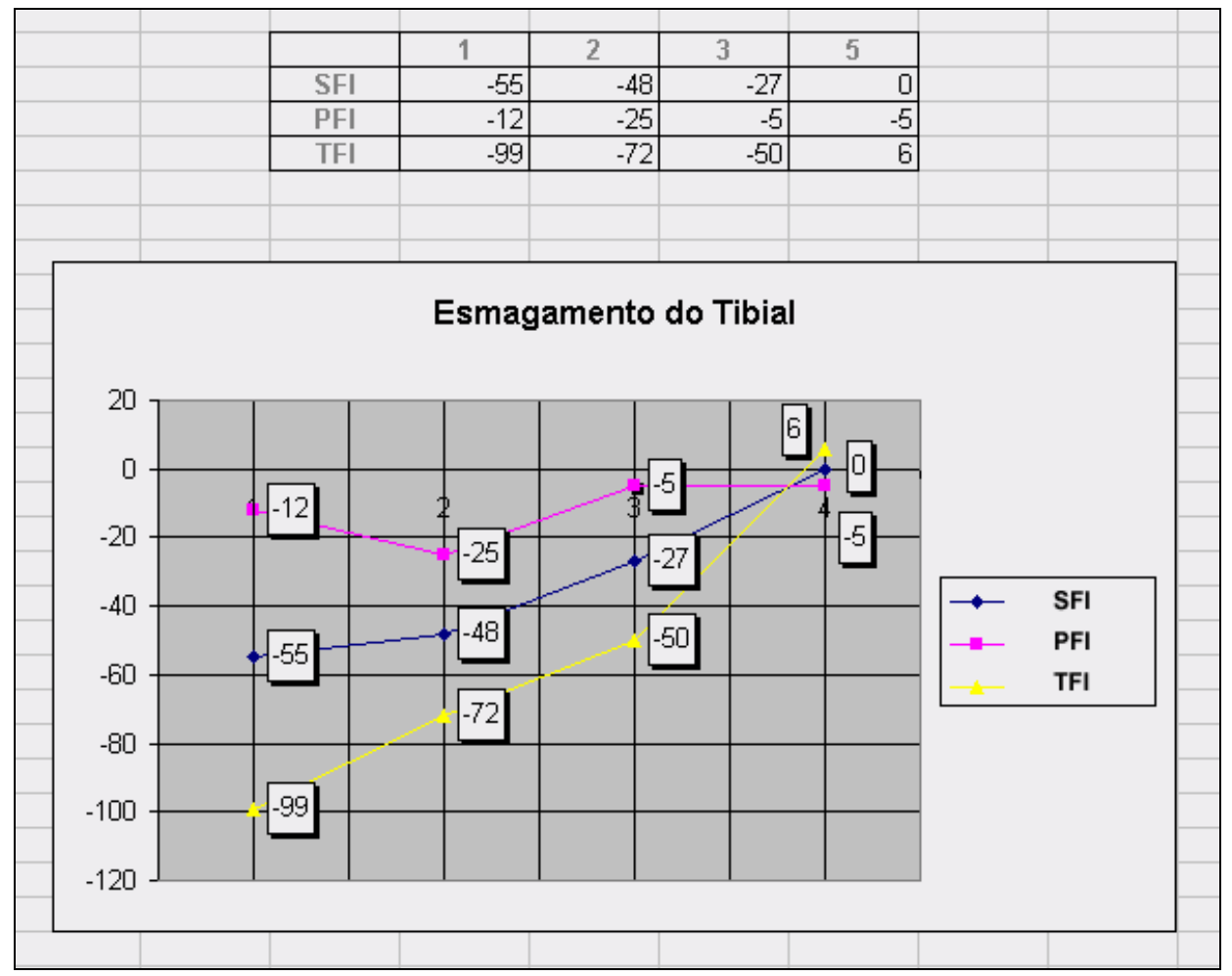

$\checkmark$ Esmagamento do Ciático

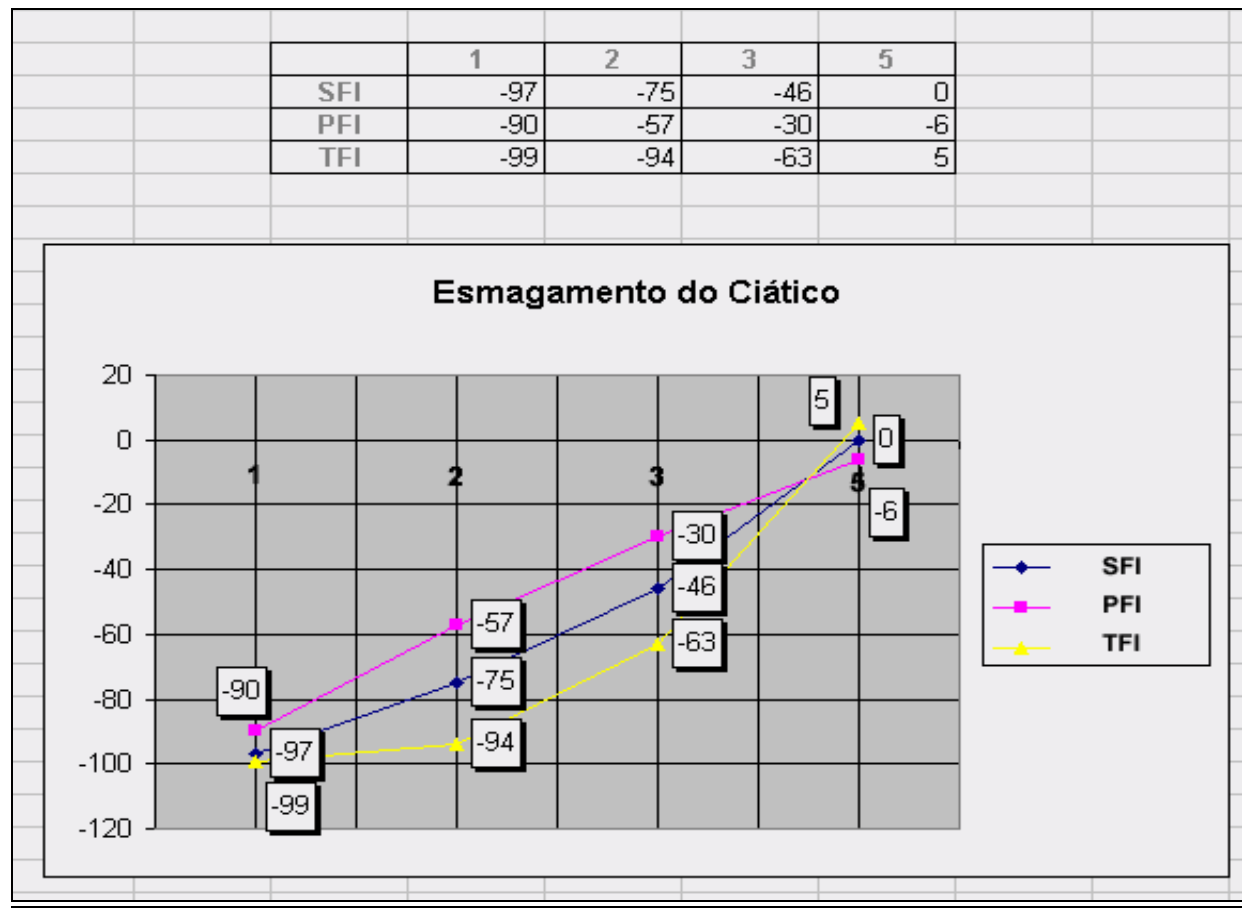


Levando em consideração que o índex igual a 0(zero) era normal e -100(cem), o prejuízo total do nervo lesionado. Após o tempo estabelecido pelos pesquisados, os índices referentes aos três nervos se normalizaram.

\subsubsection{Método de Bain, Mackinnon e Hunter (1989)}

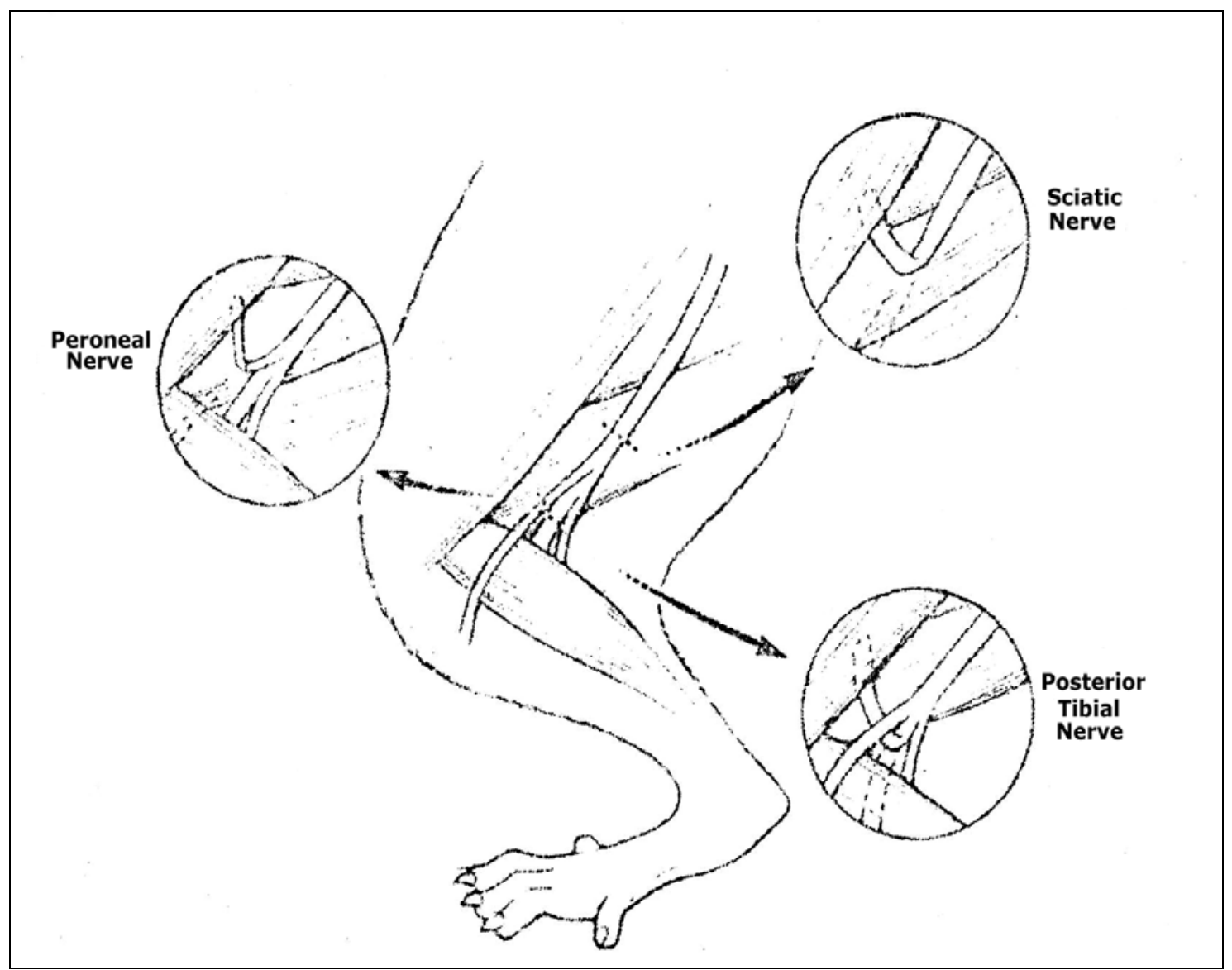

Figura 3: Procedimento experimental de Bain, Mackinnon e Hunter (1989). 
Com o objetivo de desenvolver e testar equações independentes e confiáveis para avaliações funcionais da regeneração dos nervos isquiático, tibial e fibular, um experimento foi conduzido por (Bain; Mackinnon; Hunter, 1989). Foram utilizados ratos Wistar, brancos, treinados, pesando de 200 a 250 gramas, com alimentação e ciclo de luz controlada. O procedimento cirúrgico constou basicamente da exposição do nervo isquiático e a identificação dos seus ramos, por abordagem transmuscular do glúteo maior. Os animais foram escolhidos ao acaso e distribuídos em quatro grupos, conforme o tipo de procedimento realizado:

\section{Grupo de Controle (Sham operation);}

2.Lesão completa do nervo fibular;

3.Lesão completa do nervo tibial posterior;

4.Lesão completa do nervo isquiático.

Em adição, o lado experimental também foi escolhido ao acaso em cada animal. A extremidade proximal do nervo seccionado era cuidadosamente posta em posição intramuscular e suturada no músculo glúteo. Produzida a lesão num dos ramos, os demais eram preservados.

As impressões da marcha dos animais foram obtidas em tiras de filme de raios $\mathrm{X}$ de 8,2 x $42 \mathrm{~cm}$ identificadas apenas com o número do animal testado, sendo que as patas dos animais foram umedecidas em solução reveladora, segundo o método de (De 
Medinaceli; Freed; Wyatt, 1982). Várias pegadas foram registradas em cada filme. Algumas, de leitura impossível devido ao arraste da cauda do animal ou à sobreposição das pegadas, foram desprezadas. As seguintes medições foram efetuadas:

1.TOF (to opposite foot): distância ao pé oposto;

2.PL (print length): comprimento da pegada;

3.PA (print angle): distância entre a pegada e a linha média da marcha

4.TS (toe spread): distância do primeiro ao quinto dedos;

5.IT (intermediate toes spread): distância entre o segundo e quarto dedos.

As medições foram feitas para as pegadas experimentais e para as normais, rotuladas respectivamente com E e N. Por exemplo, NTOF representa a distância entre o maior dedo da pegada normal e o maior dedo da pegada operada.

Em geral, foi notada uma excelente constância nos parâmetros das diferentes pegadas numa mesma trilha. Porém, para maior rigor matemático, era utilizada em cada registro a máxima distância medida. As medidas foram feitas numa mesa digitalizadora (Hipad Digitzer, Houston Instruments, Austin, Texas), ligada a um computador pessoal (IBM PCXT, IBM Armonk, N.Y.), utilizando um software de morfometria (Bioquant II, R\&M Biometrics, Nashville, Tenn.). 
Um fator foi gerado a partir de cada uma das medidas de marcha por meio da subtração de valores normais e experimentais e dividindo-se esta diferença pela medida normal:

FatorGerado $=\frac{\text { ValorExperimental }- \text { ValorNormal }}{\text { ValorNormal }}$

Obtendo assim:

\begin{tabular}{lcc}
\hline & Fatores & \\
\hline Distância ao pé oposto & TOF & (ETOF-NTOF)/NTOF \\
Comprimento da pegada & PFL & (EPL-NPL)/NPL \\
Ângulo da pegada & PAF & (EPA -NPA)/NPA \\
Espalhamento dos dedos & TSF & (ETS-NTS)/NTS \\
\hline
\end{tabular}

Tabela 1: Fatores

Na análise de regressão linear múltipla, os fatores criados foram entrados como variáveis independentes. A regressão utilizou como a variável dependente o déficit do nervo (índice funcional do isquiático, com o valor de -100 (cem) em animais com o nervo isquiático seccionado e de zero em animais do grupo de controle; e índice 
funcional fibular, com o valor de -100 em animais com o nervo fibular seccionado e de 0 (zero) em animais do grupo controle).

Pela primeira vez neste tipo de estudo, foram feitas análises da variância significativa das variáveis nas trilhas e dos fatores criados. As análises foram feitas da seguinte maneira:

1. Foi estabelecido que cada uma das variáveis medidas na pegada normal (NTOF, NPL, NPA, NTS, NIT) não poderia ter, entre os diferentes grupos, variância significativa. Como resultado dessas análises, todas as variáveis normais foram aprovadas.

2. Foi estabelecido que as variáveis medidas na pegada experimental (ETOF, EPL, EPA, ETS, EIT) devem ter necessariamente variância significativa entre os diferentes grupos. Nesta análise, a variável EPA (Ângulo da pegada experimental) não teve variação dependente das lesões seletivas causadas em cada grupo, tendo sido reprovada e retirada do procedimento. Não foi notada variância significativa entre lados operados num mesmo grupo.

3. Analogamente, foi estabelecido que os fatores estudados (PFL - fator comprimento da pegada, TSF - fator espalhamento de dedos, ITF - fator espalhamento intermediário, TOF - fator distância ao pé oposto) devem necessariamente ter variância significativa entre os grupos, uma vez que devem ser correlacionados com as lesões seletivas. O fator PAF (fator ângulo da pegada) não participou do ensaio, porque a variável experimental EPA (ângulo de pegada experimental) que compõe o fator foi 
excluída anteriormente. Pelos testes realizados, foi constatada a inexistência de variância significativa entre grupos para o fator TOF. Os demais fatores (PLF, TSF ITF) foram aprovados e, portanto, utilizados nas equações.

Após as medições e seleção das variáveis a serem usadas, e de posse da matriz de constantes de peso (tipo $\{b 1$, b2,... bn $\}$ ) resultante da análise de regressão linear múltipla, foram determinadas as equações para os índices funcionais independentes dos nervos isquiático, fibular e tibial posterior, como seguem:

$S F I=-38.3 \times\left(\frac{E P L-N P L}{N P L}\right)+109.5 \times\left(\frac{E T S-N T S}{N T S}\right)+13.3 \times\left(\frac{E I T-N I T}{N I T}\right)-8.8$

$T F I=-37.2 \times\left(\frac{E P L-N P L}{N P L}\right)+104.4 \times\left(\frac{E T S-N T S}{N T S}\right)+45.6 \times\left(\frac{E I T-N I T}{N I T}\right)-8.8$

$P F I=174.9 \times\left(\frac{E P L-N P L}{N P L}\right)+80.3 \times\left(\frac{E T S-N T S}{N T S}\right)-13.4$ 


\subsection{Métodos de Registro da Marcha}

\subsubsection{Utilização de Filmes de Raios X}

(De Medinaceli; Freed; Wyatt, 1982) utilizaram-se de tiras de filme de raios X para obterem o registro do padrão da marcha de ratos. Os animais, com as patas umedecidas em solução reveladora, eram postos a caminhar por sobre esse filme, numa passarela especialmente construída, deixando dessa maneira a impressão da marcha. Outros grupos de pesquisadores utilizaram-se do mesmo método posteriormente (De Medinaceli; Derenzo; Wyatt, 1984), (Carlton; Goldberg, 1986) e (Bain; Mackinnon; Hunter, 1989).

\subsubsection{Utilização de Papel Azul de Bromofenol}

(Lowdon; Seader; Urbaniak, 1988) descreveram um método alternativo ao das tiras de filme de raios $\mathrm{X}$ para registro de pegadas, propondo o uso de tiras de papel, nas mesmas dimensões usadas com os filmes e tratadas com uma solução a 0,5\% de anidrosulfona de azul de bromofenol em acetona. Depois de secas, as tiras de papel 
assim tratadas adquirem uma coloração laranja e necessitam de acondicionamento em local seco, pois a umidade as torna paulatinamente azuladas.

Os autores testaram o método num ensaio com 20 ratos Wistar adultos, comparando-o com as tiras de filme de raios $\mathrm{X}$. Para cada um dos métodos, foi calculado o índice funcional do isquiático de (De Medinaceli; Freed; Wyatt, 1982) por dois observadores diferentes. No resultado, não foi encontrada diferença significativa entre as médias observadas nos dois métodos (t-test). Entretanto, os coeficientes de correlação para os valores lidos pelos observadores das trilhas foram:

\begin{tabular}{lc}
\hline \multicolumn{1}{c}{ Material } & Coeficiente \\
& $\begin{array}{c}\text { De } \\
\text { Correlação }\end{array}$ \\
\hline Papel Azul de Bromofenol & 0.93 \\
Filme de raios X & 0.81 \\
\hline
\end{tabular}

Tabela 2:Correlação dos Métodos de Registro de Marcha

Outra observação importante foi à necessidade de repetição do teste em seis vezes para cada rato em média para o filme de raios $\mathrm{X}$ e de uma trilha em uma vez para o papel. Foi constatado também que o método do papel impregnado com azul de bromofenol custou cerca de um trinta avos (1/30) do método do filme (LOWDON, 1988). O preparo das tiras de papel é simples e rápido, e seu funcionamento é adequado, se a secagem e estocagem forem satisfatórias. 


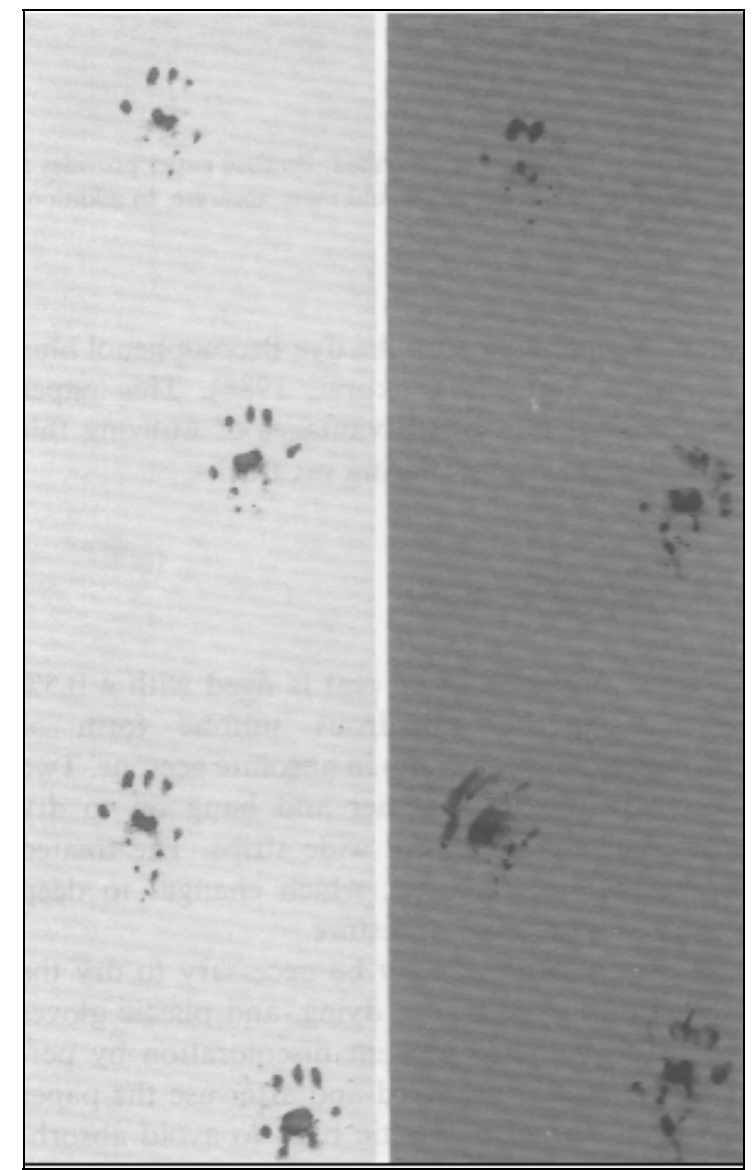

Figura 4: Comparação entre os métodos de registro de marcha. À direita o registro utilizando filmes de raios $X$, e à esquerda o registro utilizando método de Lowdon, Seader e Urbaniak (1988). 


\section{Objetivo}

O objetivo deste trabalho foi implementar um software de interface amigável, flexível e eficiente na análise de nervos periféricos do isquiático, tibial e fibular na obtenção dos índices funcionais, segundo os métodos de Medinaceli, (Freed; Watt, 1982), (Carlton; Goldberg, 1986) e (Bain; Mackinnon; Hunter, 1989). O enfoque interativo para com o usuário é apresentado pelo sistema, tornando, assim, rápido o entendimento e o desenvolvimento do processo proposto. 


\section{Materiais}

Neste sistema, os materiais utilizados são as impressões de marcha, as pegadas que são digitalizadas pelos usuários e transformadas em informações de entrada de dados para o sistema.

Nos equipamentos, representados pelo hardware, tivemos a utilização de scanner, impressora e um computador do tipo PC-AT.

Completando os materiais, estão os aplicativos auxiliares e ambientes de desenvolvimento integrados (IDEs), que atuaram em todas fases de desenvolvimento do software, desde a análise dos requisitos até a documentação e a transmissão do conhecimento.

\subsection{Impressão da Marcha}

O método de impressão utilizado no sistema foi o descrito por (Lowdon; Seader; Urbaniak, 1998) que emprega papel xerox de medida $(8,2$ x $42 \mathrm{~cm})$ é tingido com uma solução de $0,5 \%$ da fórmula de anidrido sulfônico de Bromofenol Azul (Sigma) em absoluta acetona. Entretanto, o método de impressão da marcha com filme de raios $\mathrm{X}$ pode ser também utilizado neste sistema, desde que sejam consideradas as avaliações que foram feitas no item Métodos de Registro da Marcha neste documento. 


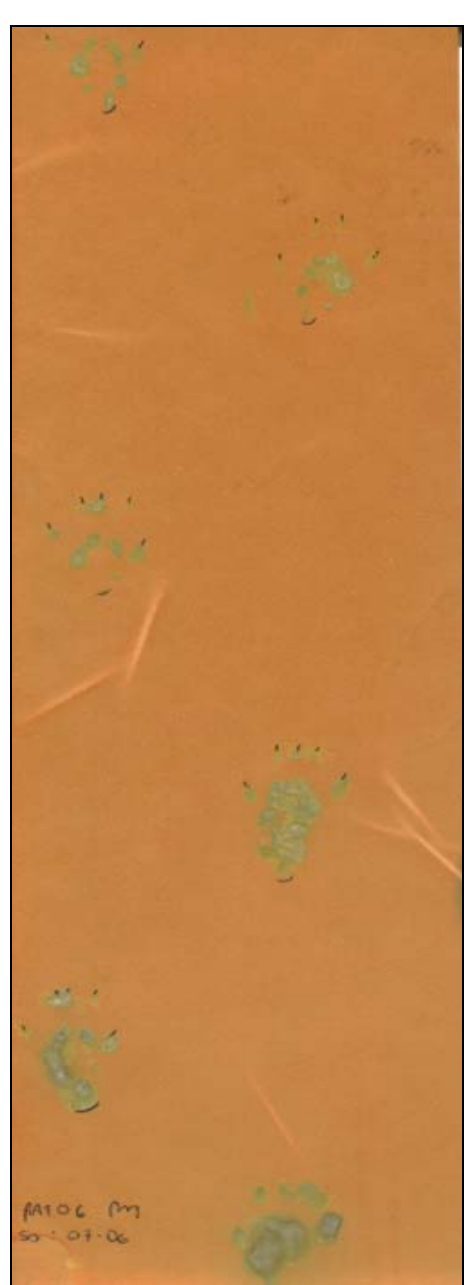

Figura 5: Registro obtido da trilha,segundo o método de Lowdon, Seader e Urbaniak (1988)

\subsection{Ferramentas de Implementação}

Devido à necessidade de realizar a persistência das informações, os dados são armazenados neste sistema, a fim de serem depois restaurados para realizar as avaliações funcionais, e a utilização de um banco de dados passou a ser considerada como um dos escopos no projeto do sistema (DBMS - Database Management System); a fim de que funcionalidades necessárias às ferramentas de implementação (softwares) 
que serão utilizadas para a geração do aplicativo, alvo da avaliação funcional dos nervos isquiático, fibular e tibial:

1.Banco de dados projetado para armazenar e manipular as informações;

2.Linguagem UML usada para especificar, visualizar e documentar um sistema de software;

3.Linguagem de programação com capacidade para desenvolver interfaces rápidas e amigáveis para o usuário, com suporte também para os cálculos dos índices funcionais;

4.Linguagem de programação com interface eficiente para a comunicação com banco de dados;

5.Ferramenta utilizada para desenvolver tópicos de ajuda;

6.Ferramenta utilizada para desenvolver instalador de sistemas.

\subsubsection{Hardware Utilizado}

No desenvolvimento do projeto, foram utilizados os seguintes elementos de hardware: 
$\checkmark$ Microcomputador PC AT Pentium III de 700 MHz, com 128 Mbytes de memória RAM e disco rígido de 10 Gbytes e monitor colorido padrão SVGA de 15 polegadas;

$\checkmark$ Impressora HP Deskjet 930C com 4 Mbytes de memória RAM para a impressão dos relatórios;

$\checkmark$ Scanner colorido de mesa Genius com 9600 dpi de resolução para a digitalização das pegadas;

\subsubsection{Software Utilizado}

No desenvolvimento do projeto, foram utilizados os seguintes softwares:

$\checkmark$ Sistema operacional da Microsoft Windows 2000 com service pack 3;

$\checkmark$ Compilador e IDE (Integrated Development Environment - Ambiente de Desenvolvimento Integrado) para o desenvolvimento do sistema, Microsoft Visual Basic 6.0 - 32 bits com service pack 5;

$\checkmark$ Gerenciador de banco de dados Microsoft Access 2000 com service pack 2;

$\checkmark$ Seagate Crystal Reports 8.0.1.0 para a geração dos relatórios; 
$\checkmark$ Microsoft Word 2000 com service pack 2 para a documentação e a formatação do projeto;

$\checkmark$ O Paint Shop Pro 8 para aquisição e armazenamento de imagens via scanner;

$\checkmark$ Robohelp 2000 para a criação de soluções de ajuda, ou seja, o Help dentro do sistema;

$\checkmark$ Installshield Express 2.13 para a criação de um instalador do sistema;

$\checkmark$ O software Rational Rose 2000 para a documentação da fase de análise do projeto;

$\checkmark$ Microsoft Power Point 2000 com service pack 2 para a criação da apresentação do projeto;

$\checkmark$ Camtasia Studio2 para a criação das apresentações do software no projeto em arquivos de vídeos. 


\section{Métodos}

A descrição dos métodos utilizados neste trabalho visa a esclarecer os procedimentos de elaboração do software AFNP, uma vez que a aplicação do método informatizado de avaliação funcional é o objetivo deste trabalho.

\subsection{Linguagem Modelagem Unificada - UML}

O UML (Unified Modeling Language) é uma linguagem-padrão para documentar projetos de software. Pode ser usado para visualizar, especificar e construir os elementos de um sistema baseado em software, a fim de conseguirem atingir os requisitos pretendidos para o projeto, pois um projeto não pode jamais tolerar perspectivas individualizadas que acabam determinando o fracasso até de um projeto.

Como o UML é uma linguagem, que provê de um vocabulário e de um conjunto de regras para combinar os elementos da linguagem, focando nos elementos conceituais e físicos que representam um sistema.

Muitos profissionais na área de informática modelam o sistema apenas em suas mentes e, com base neste modelo mental, codificam os programas. O grande problema disso são em futuras manutenções ou melhorias que são sugeridas para o sistema, os 
programadores nesta etapa encontra-se sem nenhuma documentação, tendo apenas o código implementado. Por isso, com o UML, o desenvolvedor tem a possibilidade de documentar e modelar todo o seu sistema.

Na especificação deste sistema diante de uma visão lógica foi utilizado o diagrama, usado para modelar partes específicas do sistema, como foram os requisitos funcionais, por meio do diagrama de caso de uso e o de estados.

\subsubsection{Caso de Uso}

O comportamento de um sistema é a funcionalidade necessária a ser fornecida pelo sistema que é documentado em um modelo que ilustra as funções pretendidas do sistema chamado “Casos de Usos”. O seu papel mais importante é a comunicação, onde ele é um veículo usado pelos clientes ou usuários finais e desenvolvedores para discutir a funcionalidade e o comportamento do sistema. O caso de uso é a ferramenta UML que focaliza o quê o sistema irá fazer, não como ele fará. Eles são o centro a partir do qual são derivados todos os requisitos.

A completude da documentação depende do quão crítico é o caso de uso. É necessário descrever o comportamento do sistema sem excesso nem exageros de detalhes, sem se preocupar com as tecnicalidades a serem empregadas. 
No software AFNP, foi utilizada uma ferramenta CASE (Computer-Aided Software Engineering) que auxilia no desenvolvimento de sistemas de informação chamada Rational Rose.

De acordo com o comportamento do AFNP, os atores, como são chamados os usuários do sistema, não são parte do sistema, eles representam qualquer um e qualquer coisa que precise interagir com o sistema. No caso deste sistema podemos exemplificar como sendo os médicos e fisioterapeutas.

Os casos de usos modelam um diálogo entre um ator (usuário) e o sistema (AFNP). Eles representam a funcionalidade oferecida pelo sistema, ou seja, quais capacidades serão oferecidas a um ator pelo sistema. 


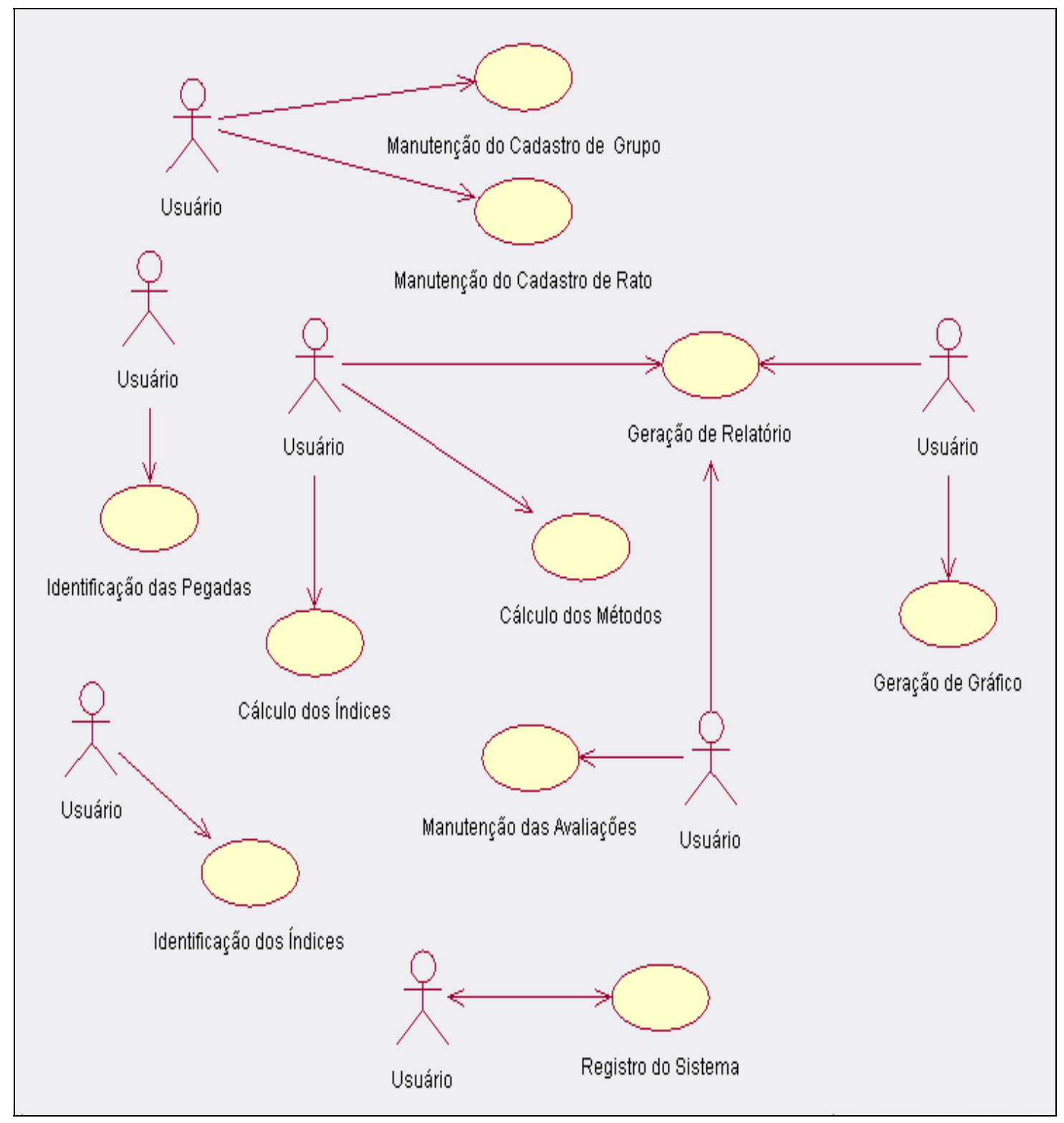

Figura 6: Caso de Uso

Sendo assim, no AFNP foram definidos os seguintes casos de usos:

- Manutenção do Cadastro de Grupo

Criar grupo;

Editar grupo; 
$>$ Remover grupo;

Pesquisar grupo;

- Manutenção do Cadastro de Rato

Criar rato;

Editar rato;

Remover rato;

Pesquisar rato;

- Identificação das Pegadas

Nomear uma pegada;

Relacionar as informações de grupo, rato e da pegada com o arquivo de imagem da pegada, segundo uma data estabelecida pelo usuário;

- Identificação dos Índices

Identificar os índices no arquivo da imagem;

• Cálculo dos Índices 
$>$ Calcular as distâncias que representam os índices no arquivo de imagem;

- Cálculo dos Métodos

$>$ Calcular os valores dos métodos, segundo os índices que fazem parte da equação do método relacionado;

- Geração de Gráfico

- Gerar gráfico de pegadas, segundo um método e um nervo relacionado em um determinado tempo;

- Manutenção das Avaliações

$>$ Pesquisa de métodos armazenados no banco de dados;

> Visualização de dados e gráficos armazenados de métodos;

• Geração de Relatório

$>$ Gerar relatório dos índices e dos métodos calculados de uma pegada;

Gerar relatório de gráficos;

Gerar relatório de histórico de avaliações;

- $\underline{\text { Registro do Sistema }}$ 
$>$ O Sistema gera uma chave de registro para a instalação do sistema;

A chave do registro gerada é validada com uma alteração que será aceita pelo sistema, liberando partes do sistema e a geração de relatórios.

\subsubsection{Diagrama de Estados}

O diagrama de estado é usado para modelar o comportamento dinâmico de um sistema. Ele mostra a seqüência de estados que um objeto ou uma interação percorre durante sua vida em resposta a estímulos recebidos, junto com suas próprias ações e respostas.

O UML utiliza a técnica gráfica de Statechart de David Harel (1987), que foi desenvolvida o comportamento complexo de um tipo de sistema em particular denominado de sistemas reativos.

Por exemplo, o comportamento de um objeto é modelado em função de qual estado ele está inicialmente, e para qual estado ele vai passar quando um determinado evento ocorrer.

Os estados representam as condições dos objetos em um determinado momento. Os eventos representam incidentes que causam a mudança de um estado para 
outro. As linhas de transição descrevem o movimento de um estado para o outro. Cada linha de transição é rotulada com o evento que causou a transição.

No AFNP, o diagrama de estados é dividido em etapas que podem ser descritas:

\section{$\checkmark$ Criação de Grupos Experimentais}

É o início real do sistema, onde o usuário insere os dados, identificando a estrutura que irá compor os experimentos realizados que são os grupos e os ratos pertencentes a estes. O primeiro evento é criar grupo. Sendo possível permanecer neste estado de criar os demais grupos ou partir para criar os ratos, que é um outro evento do diagrama, no sistema AFNP. Caso desloque para o próximo estado, terá a criação dos ratos. Após a finalização deste estado terá concretizado o final desta etapa também.

\section{$\checkmark$ Criação de Registro de Trilhas de Pegadas}

Esta etapa é definida pelo evento criar pegadas, a qual define o estado de pegadas dos ratos criadas para o registro.

\section{Medições e Cálculo dos Índices Funcionais e dos Métodos}

O primeiro evento desta etapa é de criar os índices por intermédio de uma pegada adquirida na etapa anterior, que determina o estado dos índices determinados. O próximo evento é de calcular os métodos em relação aos índices identificados. Nesta etapa ocorre o evento de calcular o desvio-padrão em relação aos valores calculados em relação ao método estabelecido pelo fator tempo. 
$\checkmark$ Visualização Gráfica da Evolução das Medidas das Pegadas

Esta etapa pode ser iniciada por dois eventos, dependendo apenas do estado a qual se queira chegar. O primeiro evento gera gráfico e o segundo, relatórios. Ambos apresentam relação com os valores calculados pelos métodos escolhidos pelo pesquisador. 


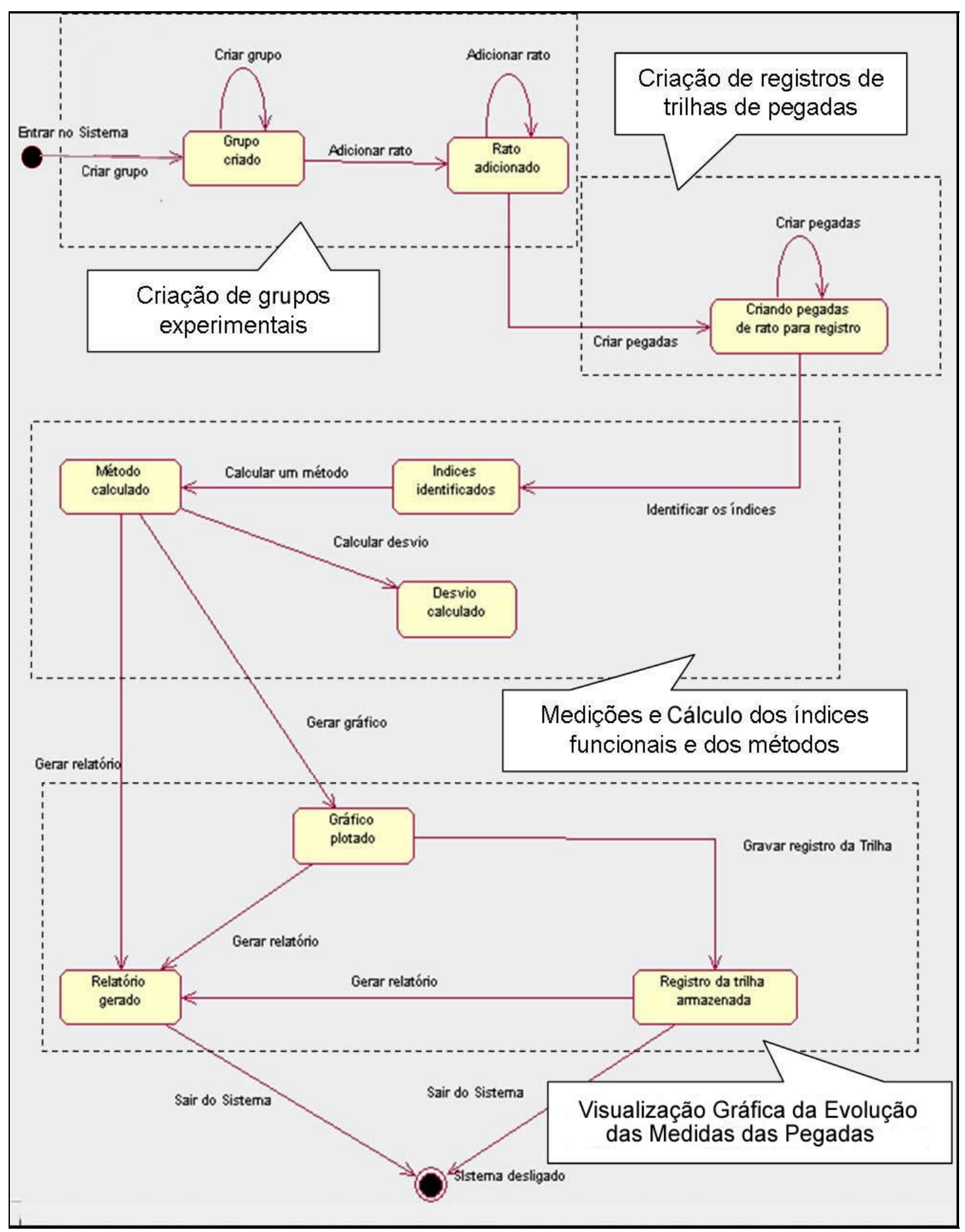

Figura 7: Diagrama de estados 


\subsection{Processo}

Para a eficácia no desenvolvimento de um projeto, sabendo que todo sistema de software é passível de mudanças e adaptações, o processo utilizado no AFNP foi o desenvolvimento iterativo e incremental, onde através de etapas de um ciclo e de ciclos de vida do sistema, buscando a maturidade, possa se chegar ao produto final, satisfazendo assim, a expectativa do usuário.

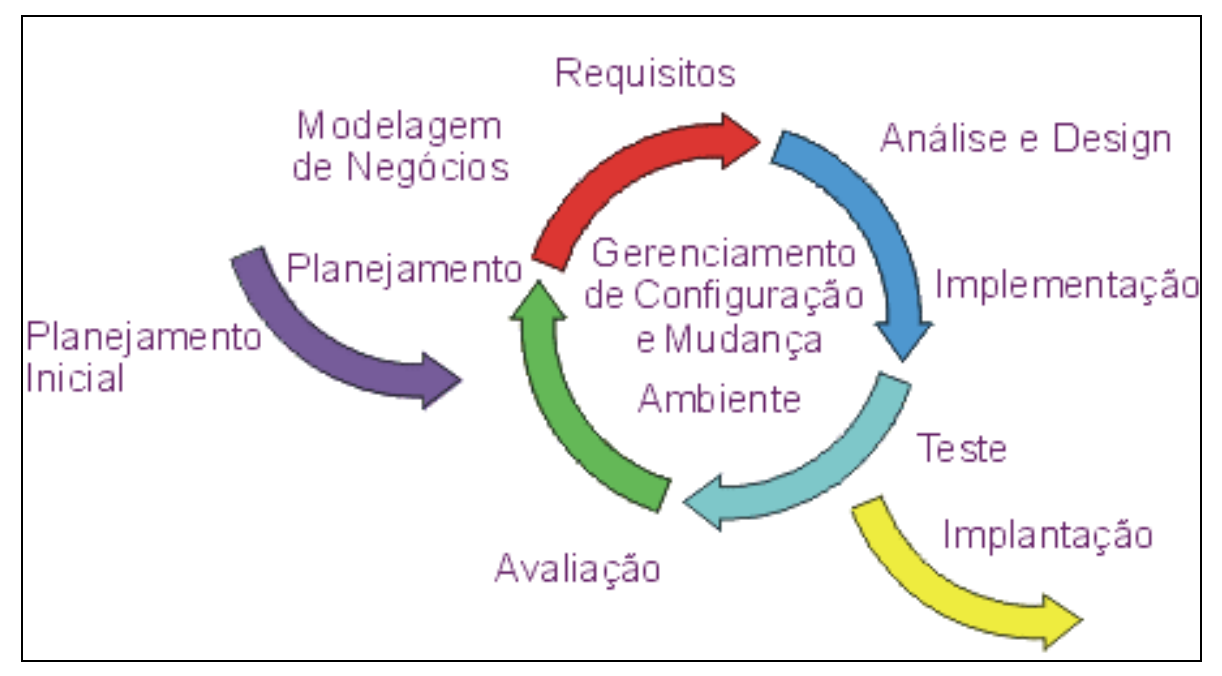

Figura 8: Ciclo de vida do desenvolvimento iterativo e incremental

Em um ciclo de vida iterativo e incremental, conforme figura 8, o desenvolvimento procede como uma série de iterações, evoluindo até alcançar o sistema final. Cada iteração consiste de um ou mais das seguintes etapas do processo. 
Esse tipo de ciclo de vida é uma maneira de avaliar o risco. Riscos técnicos são estimados e têm sua prioridade avaliada no estágio inicial do ciclo de vida, sendo revistos durante o desenvolvimento de cada iteração.

Como o AFNP é um sistema desenvolvido com a finalidade acadêmica, as fases de Requisitos e de Análise e Design foram definidas pelo nosso orientador em reuniões periódicas. E iterações do processo de desenvolvimento do sistema foram definidas em reuniões com a coordenação do nosso orientador com os usuários do sistema.

O controle para um ciclo de vida iterativo e incremental é suportado pelo emprego de Rational Unified Process - um extenso conjunto de diretrizes que encaminha os aspectos técnico e organizacional de desenvolvimento de software, focalizando todas as etapas do processo.

As etapas do processo, seguindo uma primeira dimensão, a de Componentes de processo, que é a produção de um conjunto específico de características com atividades bem definidas, são:

1.A análise de um sistema com o mesmo escopo ou de características iguais ou semelhantes do AFNP, como foi o caso do software desenvolvido pelo Selli em 1998. Etapa esta é denominada como Modelagem de Negócios, onde ocorre a identificação da capacidade das características desejadas no sistema.

2.Levantamento das exigências fornecidas pelo usuário para a melhoria na facilidade do sistema. Esta atividade segundo o RUP (Rational 
Unified Process) é chamada de Exigência, onde são identificadas as necessidades ou as exigências do usuário pelo sistema.

3.Levantamento das tecnologias existentes que serão utilizadas no sistema. Esta fase, Análise e Design, engloba a parte da descrição de como o sistema será desenvolvido e quais as características ou exigências que serão neste ciclo implementadas pelo desenvolvedor de sistemas.

4.A Implementação é a fase onde ocorre a codificação do sistema. Seja ela como no AFNP com a criação e a comunicação com a base de dados e a produção do código, com as interfaces das janelas ou da camada de apresentação e da camada de negócio do sistema.

5.Na etapa de Teste, ocorre a validação do sistema em relação aos requisitos estabelecidos no sistema e concentra-se nos aspectos lógicos do software, garantindo que toda a entrada no sistema produza resultados reais concordantes com os resultados exigidos.

6.Entrega do sistema e treinamento do usuário, definem a última etapa chamada de Implantação.

Agora analisando pela segunda dimensão do RUP, o Tempo, a divisão de ciclo de vida em fases e iterações:

1.A Modelagem de Negócios é refletida na fase de desenvolvimento da Concepção, especificando a visão do projeto. Nesta fase, é estabelecido o escopo do projeto e suas fronteiras, determinando os principais casos de uso do sistema. Esses casos de uso devem ser elaborados com a precisão 
necessária para se proceder a estimativas de prazos e custos. As estimativas devem ser globais para o projeto como um todo e detalhadas para a fase seguinte. Assim, a ênfase nesta etapa recai sobre o planejamento e, por conseguinte, é necessário levantar requisitos do sistema e preliminarmente analisá-los. Ao término dessa fase, são examinados os objetivos do projeto para se decidir sobre a continuidade do desenvolvimento.

2.As Exigências de Análise e Design pertencem à fase de Elaboração, onde o propósito desta fase é analisar mais refinadamente o domínio do problema, estabelecer uma arquitetura de fundação sólida, desenvolver um plano de projeto para o sistema a ser construído e eliminar os elementos de projeto que oferecem maior risco. Embora o processo deva sempre acomodar alterações, as atividades da fase de elaboração asseguram que os requisitos, a arquitetura e os planos estão suficientemente estáveis e os riscos estão suficientemente mitigados, de modo a se poder prever com precisão os custos e prazos para a conclusão do desenvolvimento. Sendo assim, todas as atividades necessárias são planejadas e os recursos exigidos para o sucesso do projeto.

3.A Implementação estabelece na fase onde ocorre à montagem do produto como uma série de iterações incrementais, para que esteja pronta para a transição à comunidade usuária. É denominada de Construção.

4.E a Transição, fase que ocorre o fornecimento do produto à comunidade usuária. Após o produto ter sido colocado em uso, naturalmente surgem novas considerações as quais vão demandar a construção de novas versões para permitir ajustes do sistema, corrigir problemas ou concluir 
algumas características que foram postergadas. E concentra-se nos testes, visando garantir que o sistema possui o nível adequado de qualidade. Além disso, usuários devem ser treinados, características ajustadas e elementos esquecidos adicionados.

O gráfico abaixo mostra como os componentes do processo são aplicados a cada fase baseada em tempo. Cada atividade da dimensão do componente do processo é tipicamente aplicada a cada fase da dimensão baseada em tempo. Entretanto, o grau ao qual cada componente em particular é aplicado, depende da fase de desenvolvimento.

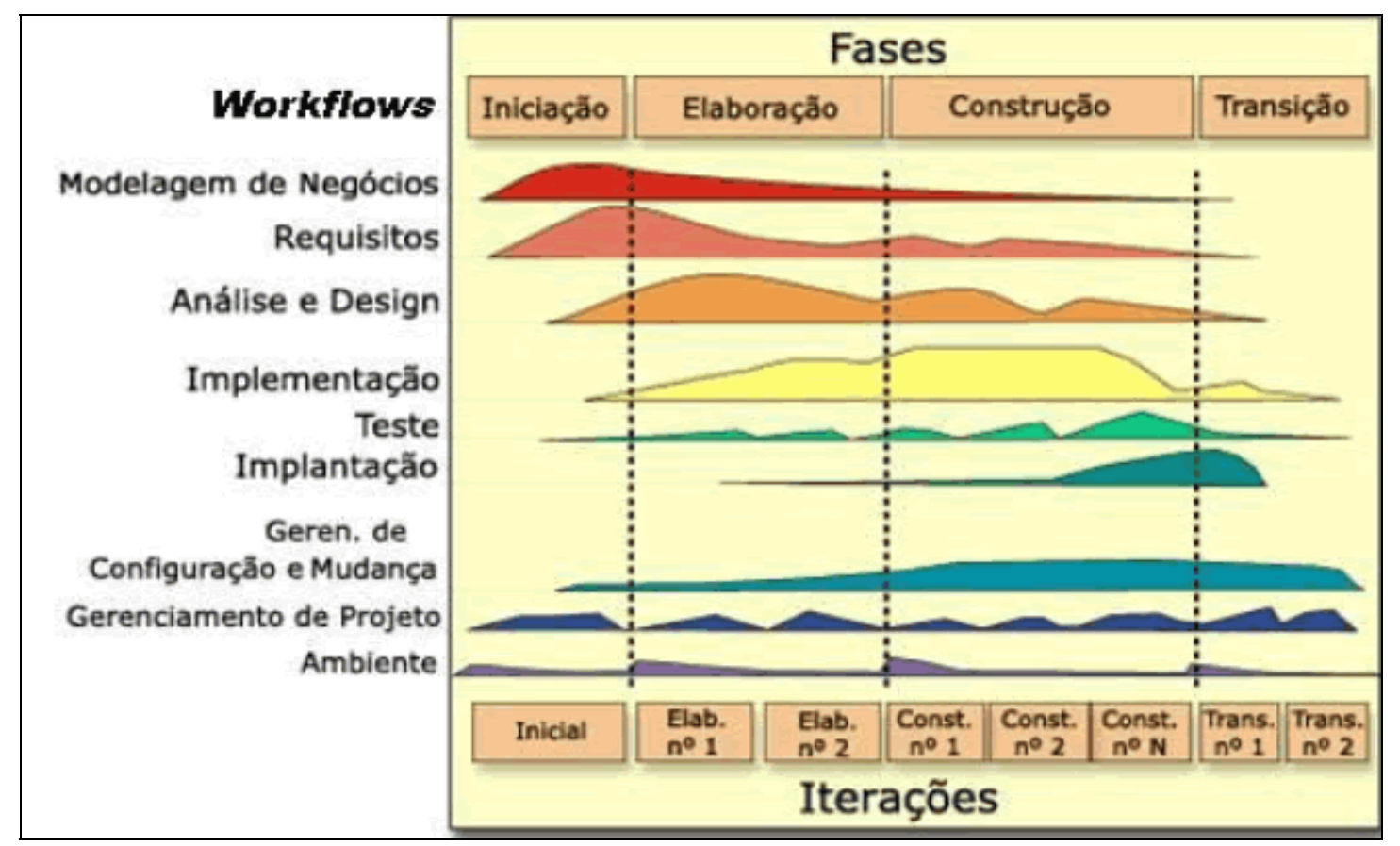

Gráfico 1: Processo de Desenvolvimento 


\subsection{Modelo de Dados}

Desde a necessidade de armazenar, encontrar e resgatar as informações de maneira rápida e eficiente, independente da quantidade de dados, os bancos de dados tornaram fundamentais nas pesquisas realizadas. Um dos exemplos são o Protein Data Bank e o Genbank.

Fundamental à estrutura de um banco de dados é o conceito de um modelo de dados, uma coleção de ferramentas conceituais para a descrição de dados, relacionamentos de dados, semântica de dados e restrições de consistência. O modelo utilizado neste sistema é o “Modelo Relacional” que representa os dados e os seus relacionamentos por um conjunto de tabelas, cada uma tendo um número de colunas com nomes únicos. O modelo relacional é uma teoria matemática desenvolvida por Ted Codd para descrever como as bases de dados devem funcionar. 


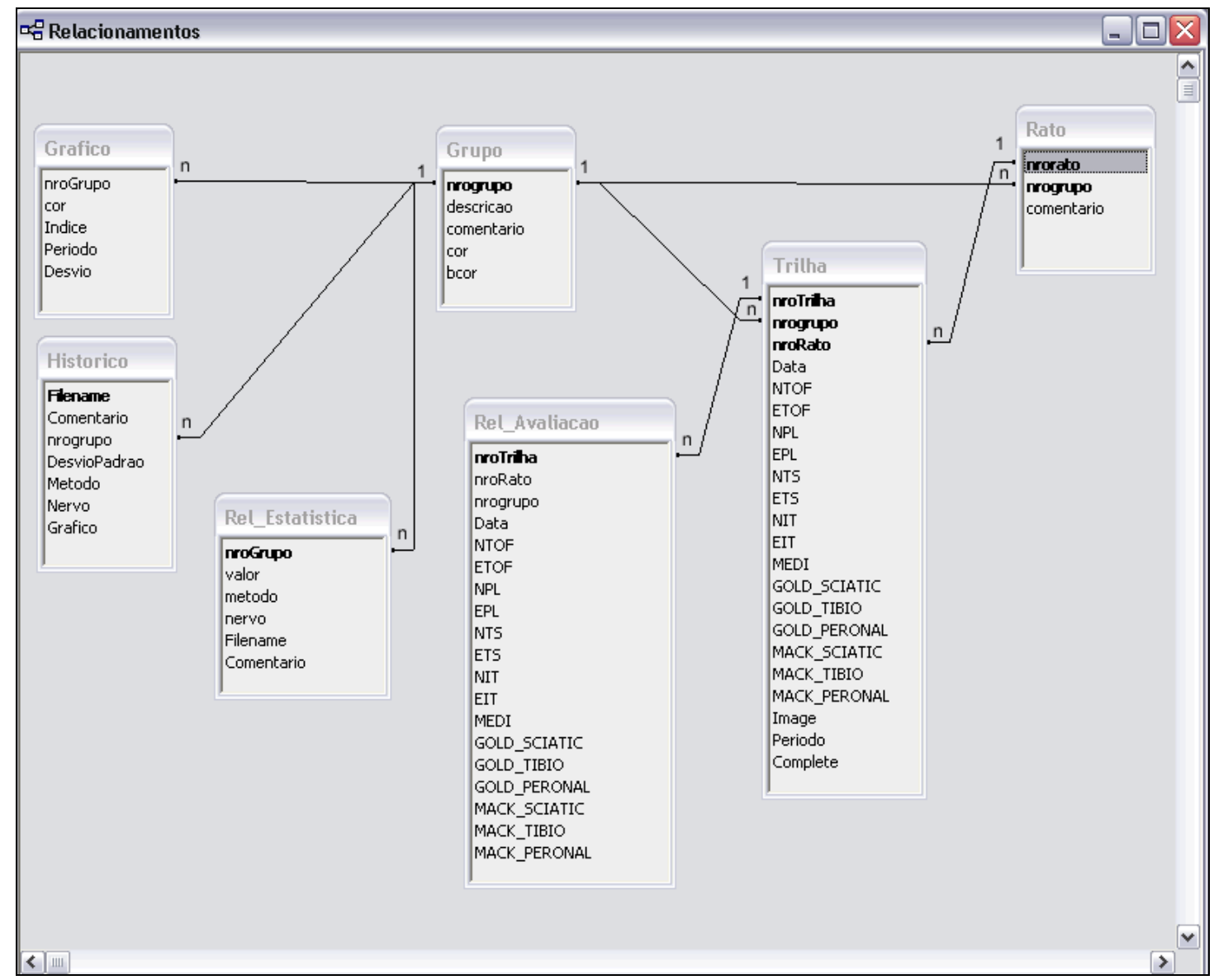

Figura 9: Visualização do Banco de Dados

As tabelas são:

$\checkmark$ Grupo: tabela que armazena os dados das informações de cada grupo.

$\checkmark$ Rato: tabela que armazena os dados das informações de cada rato.

$\checkmark$ Trilha: tabela que armazena os dados das informações de cada trilha de um rato pertencente a um grupo. 
$\checkmark$ Grafico: tabela que armazena temporariamente em relação a um grupo, o seu número, a cor personalizada para visualizar o gráfico, o tipo de índice utilizado, na qual são selecionados o tipo de método e o nervo. E por mais, o período e o valor do desvio-padrão que são calculados na janela Statistic. A finalidade desta tabela é a construção do gráfico, onde depois o usuário tem a escolha de armazenar o gráfico por meio de imagem na tabela "Histórico”.

$\checkmark$ Historico: tabela que armazena as informações para a pesquisa dos arquivos que são gerados na Janela Statistic

$\checkmark$ Rel_Estatistica: tabela que armazena os dados para visualizar o relatório da janela Statistic.

$\checkmark$ Rel_Avaliacao:_tabela que armazena os dados para visualizar o relatório da janela Evaluation.

Os relacionamentos como o próprio nome do modelo são os relacionamentos entre as tabelas existentes. Os relacionamentos são feitos para possibilitar a normalização dos dados. A normalização de dados é para evitar redundâncias dos próprios dados no sistema ou de até gerar inconsistência dos dados. E possibilitar uma maior performance nas pesquisas também. 
Analisando o relacionamento das tabelas do AFNP conforme figura 9, a estrutura relacional das tabelas segue a relação:

$\mathrm{o} 1 \rightarrow \mathrm{N}$, para as tabelas Grupo $\rightarrow$ Rato, significa que um grupo se refere a vários ratos.

$\mathrm{0} 1 \rightarrow \mathrm{N}$, para as tabelas Rato $\rightarrow$ Trilha, expressa que um rato possui várias trilhas de pegadas.

o1 $\rightarrow$ N, para as tabelas Trilha $\rightarrow$ Rel_Avaliacao, onde cada trilha terá uma avaliação segundo os cálculos dos índices e métodos escolhidos a serem avaliados.

$\mathrm{O} 1 \rightarrow \mathrm{N}$, para as tabelas Grupo $\rightarrow$ Rel_Estatistica, onde um grupo experimental se refere a vários arquivos.

$\mathrm{0} 1 \rightarrow \mathrm{N}$, para as tabelas Grupo $\rightarrow$ Grafico, onde cada grupo pode ter vários gráficos.

$\mathrm{O} 1 \rightarrow \mathrm{N}$, para as tabelas Grupo $\rightarrow$ Historico, onde são armazenados históricos de experimentos analisados segundo os grupos. 
Legenda: $1 \rightarrow \mathrm{N}$ : um para muitos. 


\section{Resultados}

O trabalho resultou num software flexível para o usuário, onde basta o pesquisador copiar o arquivo “usp.mdb” que contém todos os seus dados e as imagens contidas no diretório “Image” da sua instalação. Assim, caso precise utilizar as informações em um outro lugar, basta o usuário do sistema instalar o software novamente e substituir o arquivo “usp.mdb” da instalação e copiar as imagens para o diretório “Image”.

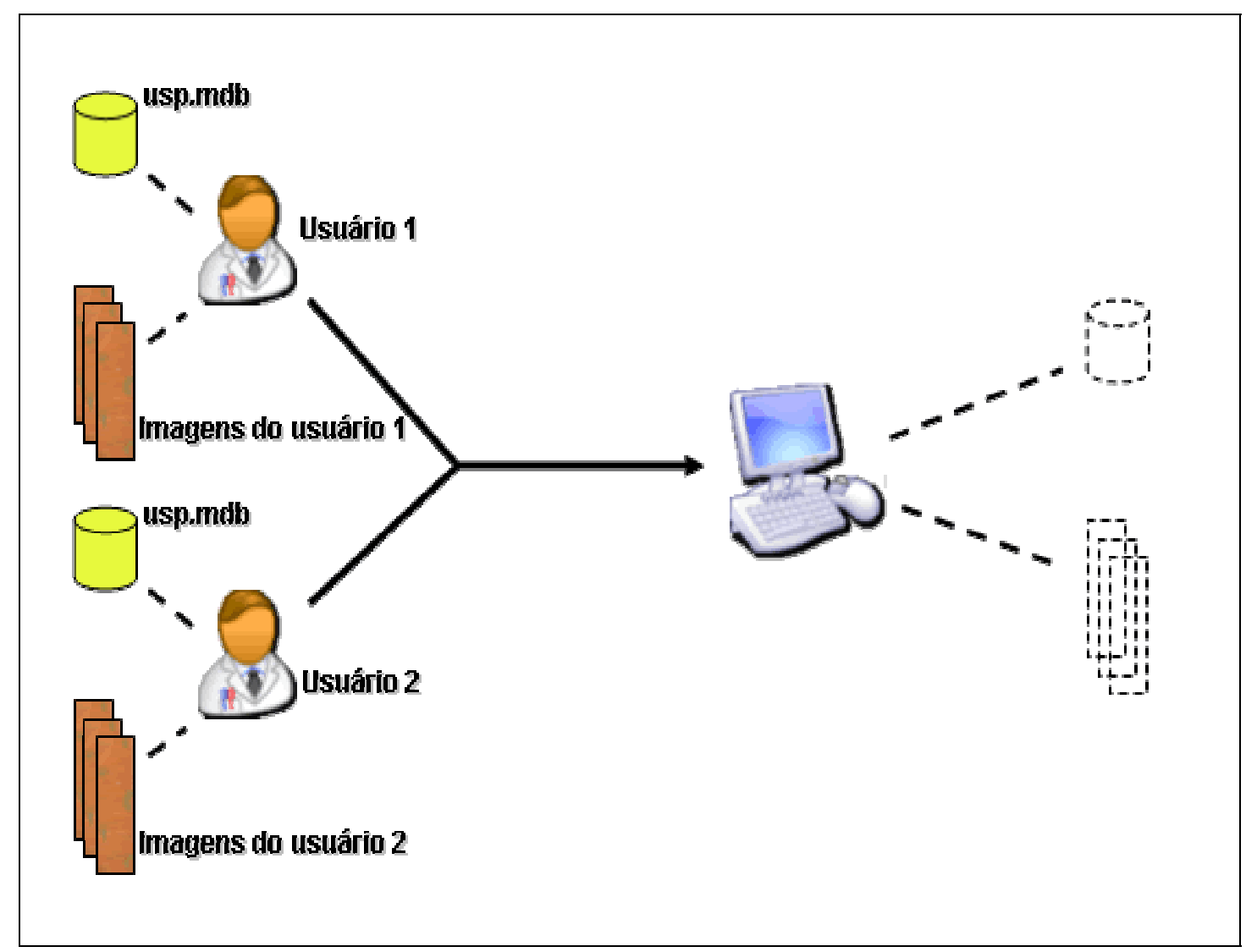

Figura 10: Flexibilidade do AFNP 
Em todo o sistema, o usuário dispõe da funcionalidade de ajuda em relação aos tópicos a ser desenvolvido em cada etapa e também em relação ao contexto. Isto é importante, pois auxilia os pesquisadores durante seus trabalhos. Tornando assim o interativo com o usuário.

Apresenta também uma interface de apresentação bastante amigável, desde a instalação a qual não requer do pesquisador nenhum pré-conhecimento e seguindo este perfil, é bem intuitivo e de fácil uso por seguir o padrão de janelas, o padrão Windows, que a maioria dos usuários se sentem já confortáveis com a utilização. Os resultados das avaliações podem ser disponibilizados na forma de gráficos e relatórios.

A alta performance do uso do software proporciona aos pesquisadores, em relação ao aumento do número de animais em grupos e também ao número maior de grupos, permite resultados estatísticos mais confiáveis e com maior aumento de precisão. Além disso, os usuários do sistema irão ter a possilibidade de realizar uma uniformidade dos métodos empregados nas pesquisas e ter como acervo todas as informações principais de análises realizadas e que foram armazenadas no histórico da ferramenta, podendo assim ser utilizadas em futuros estudo.

O usuário tem a opção de escolher entre o idioma português e o inglês em que o software será apresentado, inclusive com todo o sistema de ajuda descrito conforme o idioma selecionado. Em Configurações Regionais do sistema operacional Windows, o software detecta automaticamente o idioma português; ou em caso de outro idioma configurado, o idioma inglês, o software será apresentado. 


\subsection{Software}

\subsubsection{O AFNP}

O AFNP possui uma janela principal, orientada a menu, a qual o usuário realiza a navegação para as janelas operacionais de edições de grupos e de ratos, identificações de índices, cálculos e histórico das medições, conforme pode ser visto nas figuras.

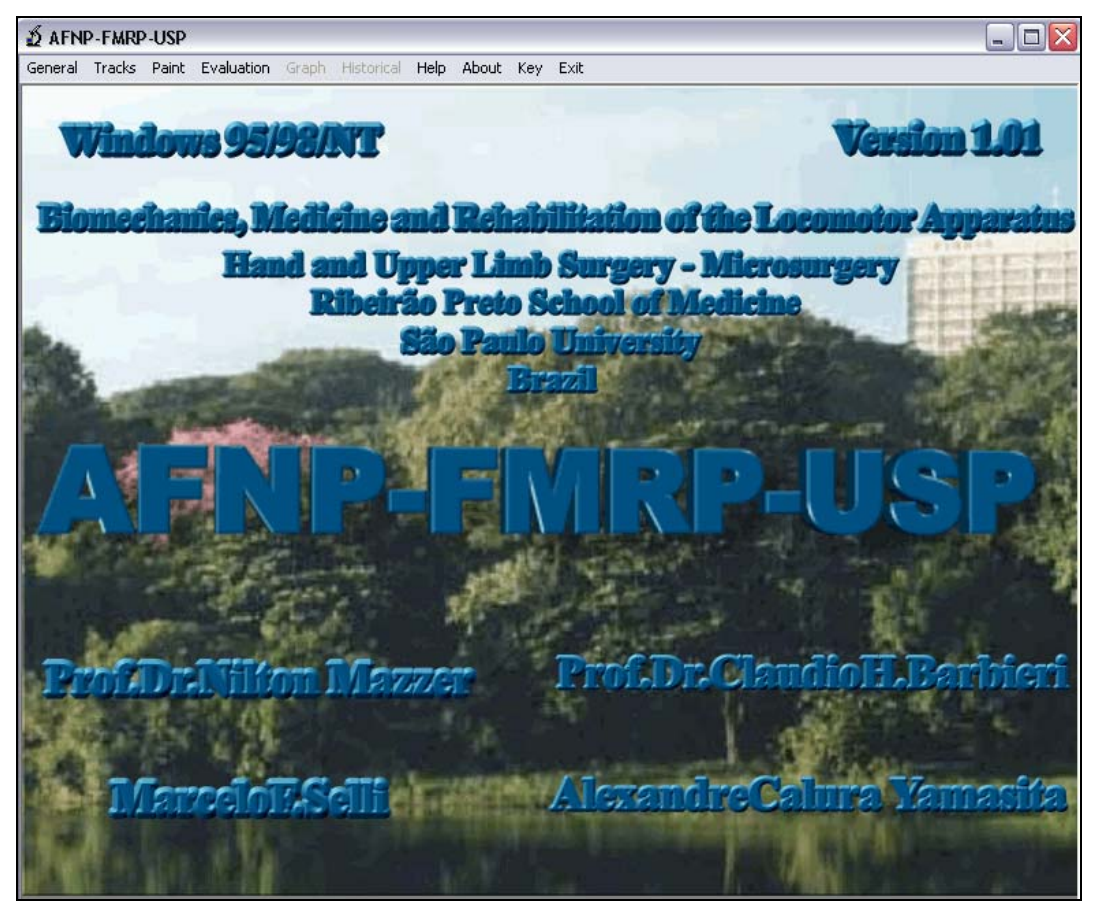

Figura 11: Janela(AFNP) - Principal do AFNP 


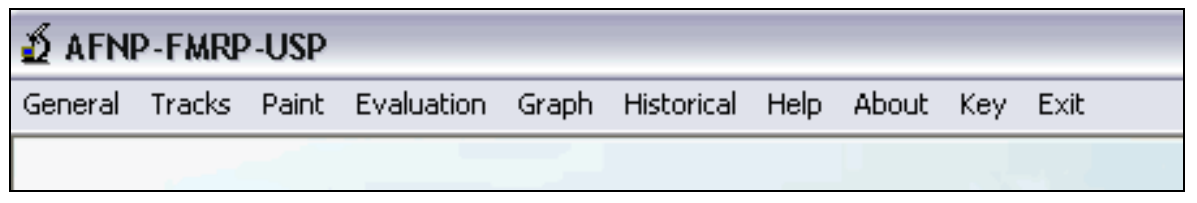

Figura 12: Menu da Janela Principal do AFNP

\subsubsection{GERAL}

Esta janela é responsável pela aquisição dos dados dos grupos e dos ratos, além da pesquisa dos mesmos. É formada por três partes:

$$
\begin{aligned}
& \checkmark \text { Grupo } \\
& \checkmark \text { Rato } \\
& \checkmark \text { Search (Pesquisa) }
\end{aligned}
$$

Sendo que o grupo e o rato possuem os seguintes métodos:

$\checkmark$ Add (adicionar)

$\checkmark$ Edit (editar)

$\checkmark$ Remove (remover) 
E os seguintes campos de entrada:

$\checkmark$ Número

$\checkmark$ Descrição

$\checkmark$ Comentário

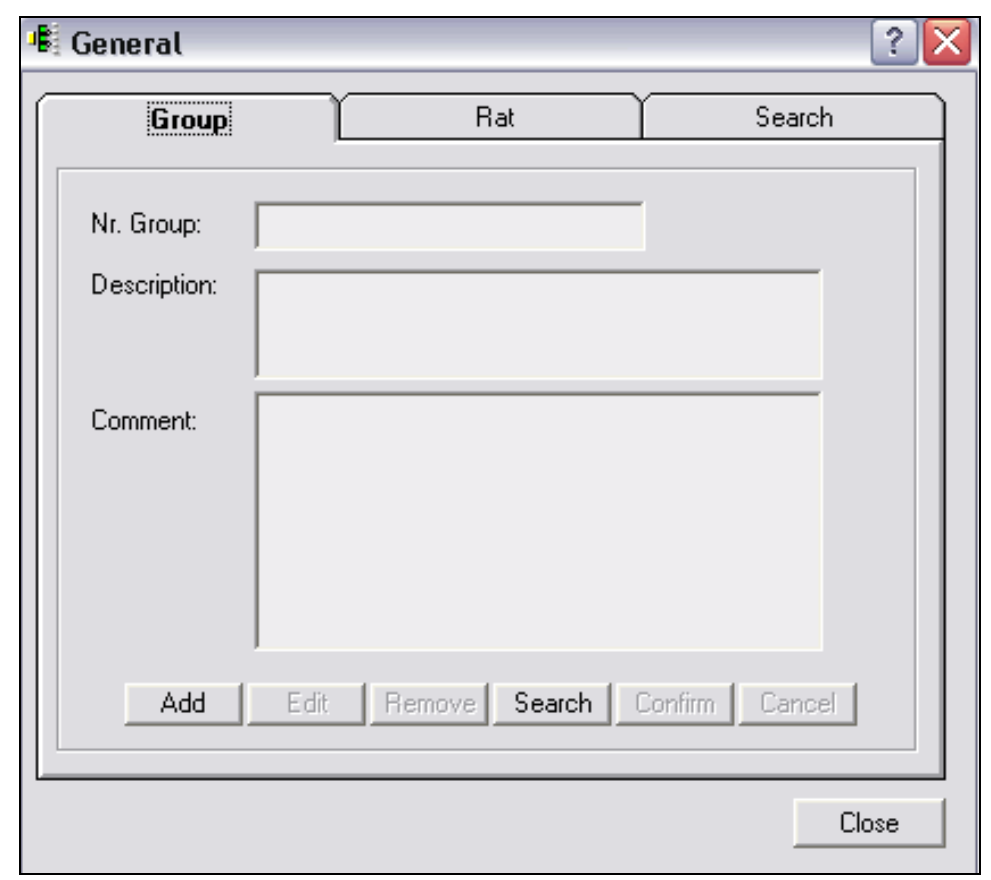

Figura 13: Janela(AFNP) - Geral -Grupo 


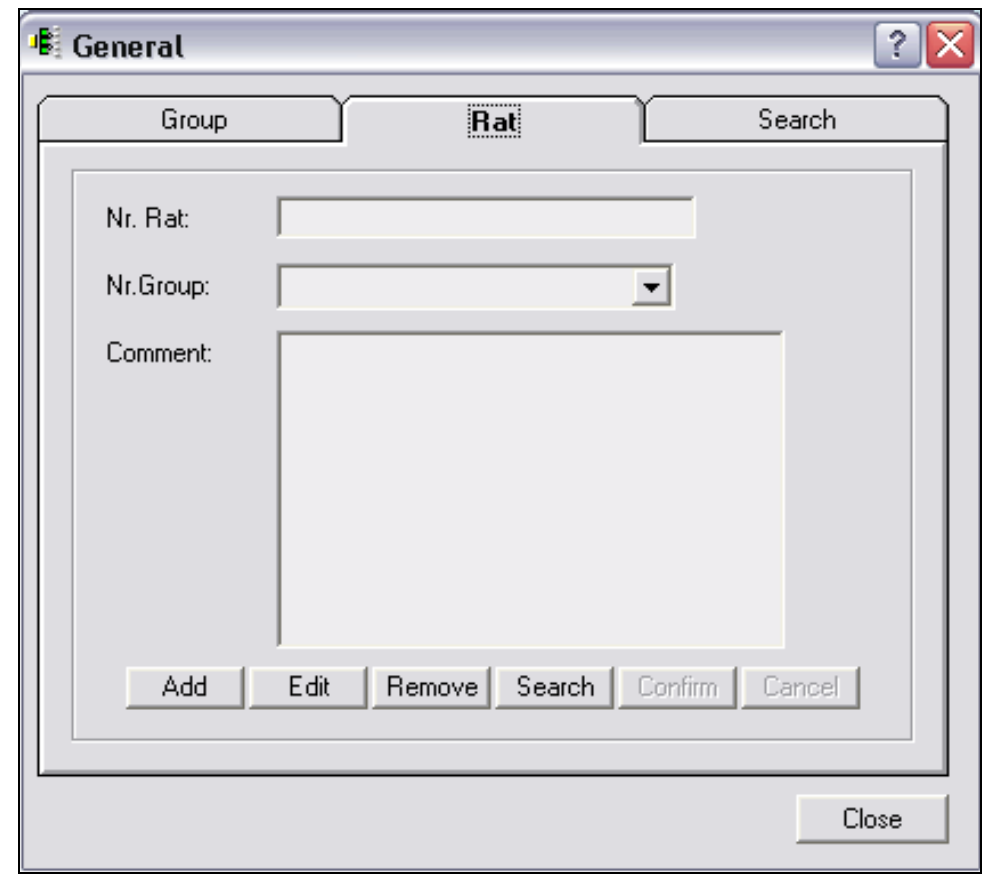

Figura 14: Janela(AFNP) - Geral - Rato

Na aba Search, o usuário tem condições de realizar pesquisas em relação ao número do rato ou pelo número do grupo.

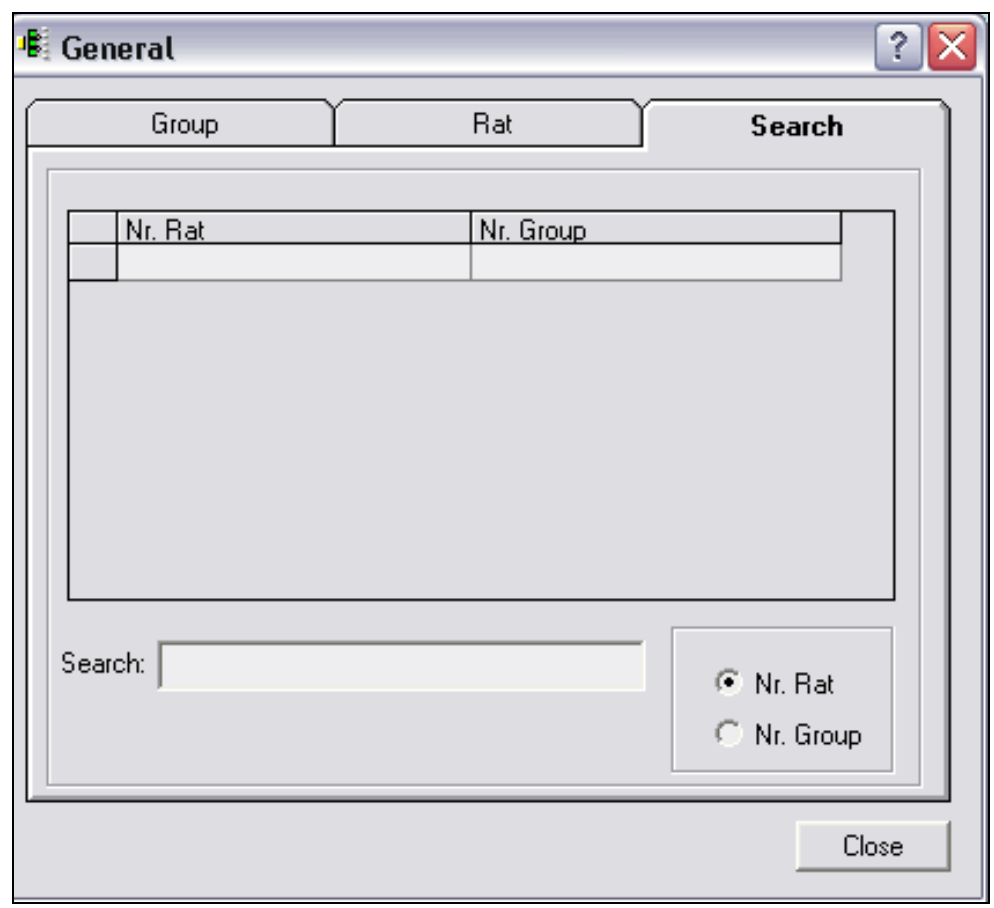

Figura 15: Janela(AFNP) - Geral-Pesquisar 


\subsubsection{TRILHAS}

Na janela de Trilhas (Tracks), o usuário seleciona qual é o arquivo de imagem que irá identificar uma determinada trilha de um determinado rato. Depois entra com o número do rato e com o número a que ele pertence. Finalizando para identificar a pegada, é dado um número à pegada do rato e a data em que foi feita a marcação da pegada.

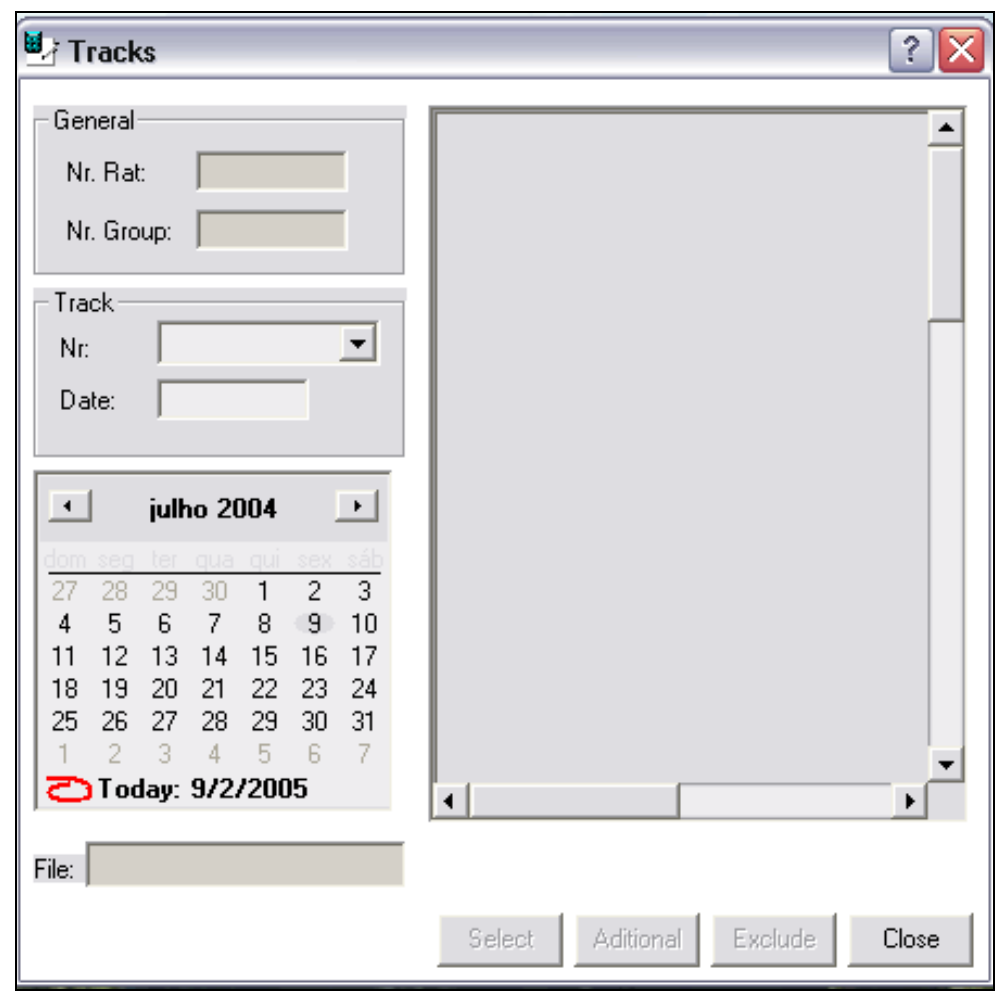

Figura 16: Janela(AFNP) - Trilhas 


\subsubsection{PINTAR}

Na janela Pintar (Paint) ocorre a marcação dos índices de medidas nas imagens. O usuário seleciona uma imagem. Depois, com a opção de selecionar uma cor e o tamanho da fonte, o pesquisador identifica com marcações pontuais e com o nome o índice desejado. Tendo assim a possibilidade de tornar melhor a visualização dos índices.

Caso ocorra um erro na marcação, o usuário tem a opção de reverter à ação utilizando o botão Undo, que defaz a última ação do usuário, considerando que ele não tenha ainda salvo a imagem. 


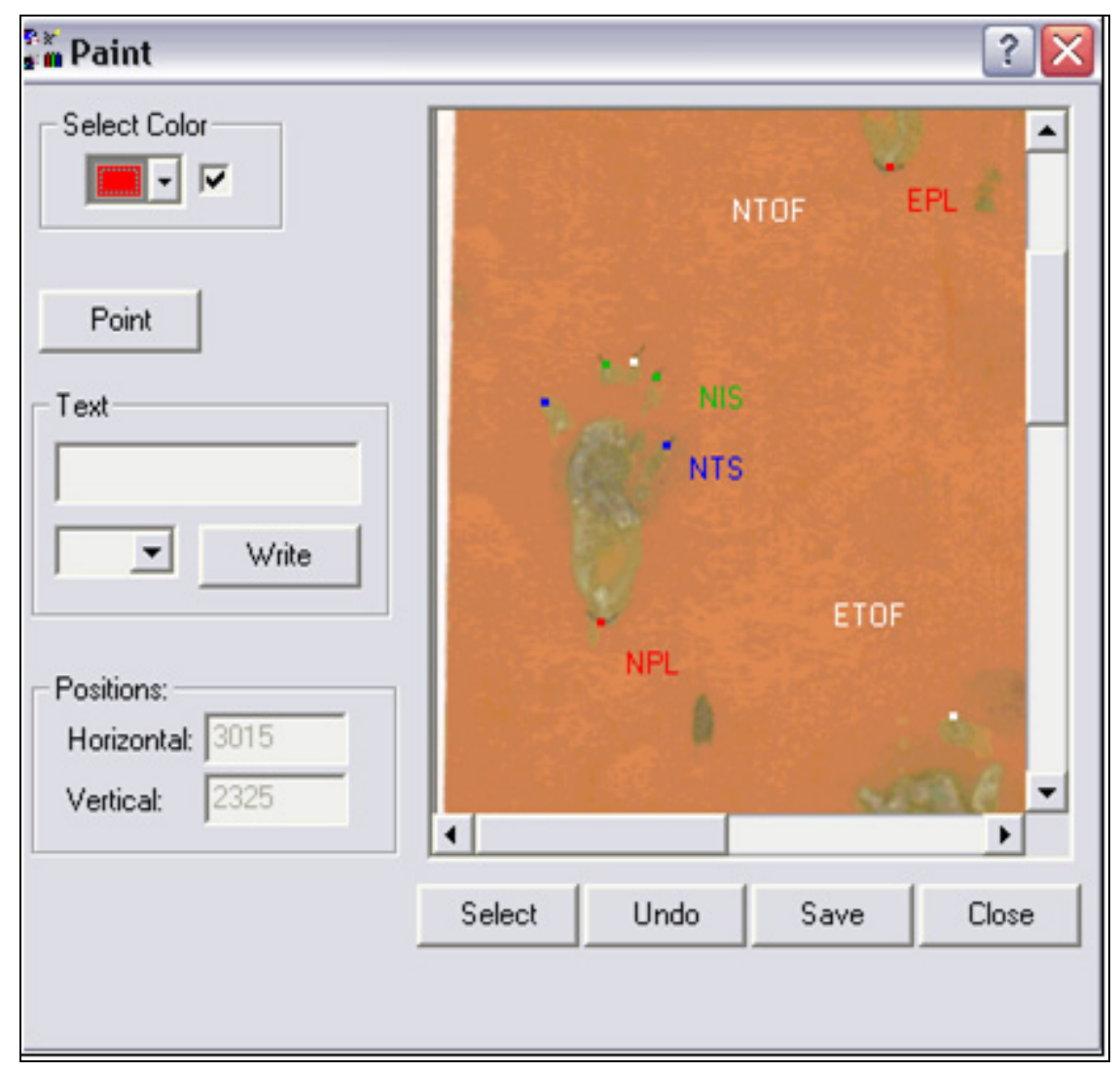

Figura 17: Janela(AFNP) - Pintar

\subsubsection{AVALIAÇÃO}

A janela Avaliação (Evaluation) é um das janelas principais do sistema. É nesta janela, onde o usuário identifica na imagem da pegada os índices de medida que são marcados na janela Paint por ele. E após serem identificados os índices de medidas, o usuário tem a possibilidade de calcular os métodos segundo os nervos.

Portanto a avaliação por meio dos métodos está relacionada com uma trilha que é representada pela imagem que foi relacionada no sistema por um número de trilha e em um período. 


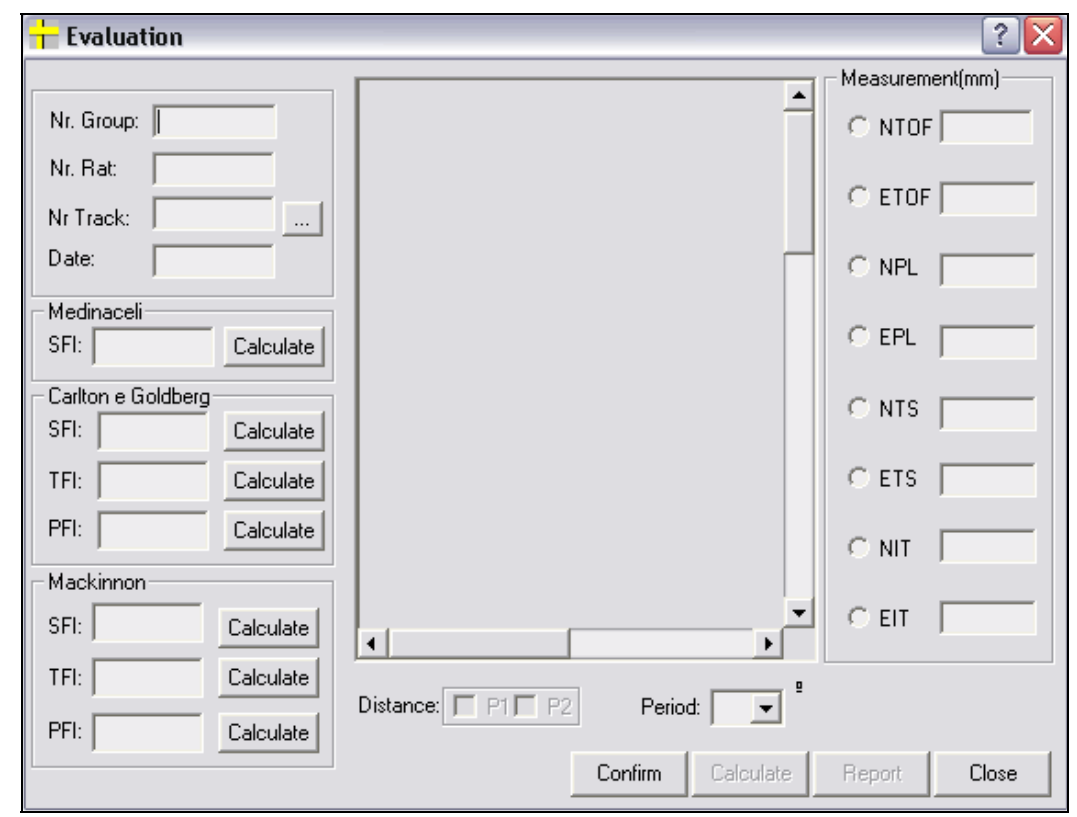

Figura 18: Janela(AFNP) - Avaliação

\subsubsection{CONFIGURAÇÃO GRÁFICA}

Na janela de Configuração Gráfica (Graph’s Configuration), o usuário seleciona os grupos que ele deseja visualizar através de um gráfico, tendo a possibilidade de selecionar como parâmetro do gráfico o tipo de método e um tipo de nervo em relação ao período do experimento. E, além disso, o usuário pode personalizar a cor que represente cada grupo no gráfico a ser visualizado. Portanto, esta janela é responsável pela configuração dos gráficos que são visualizados na janela Statistic. 


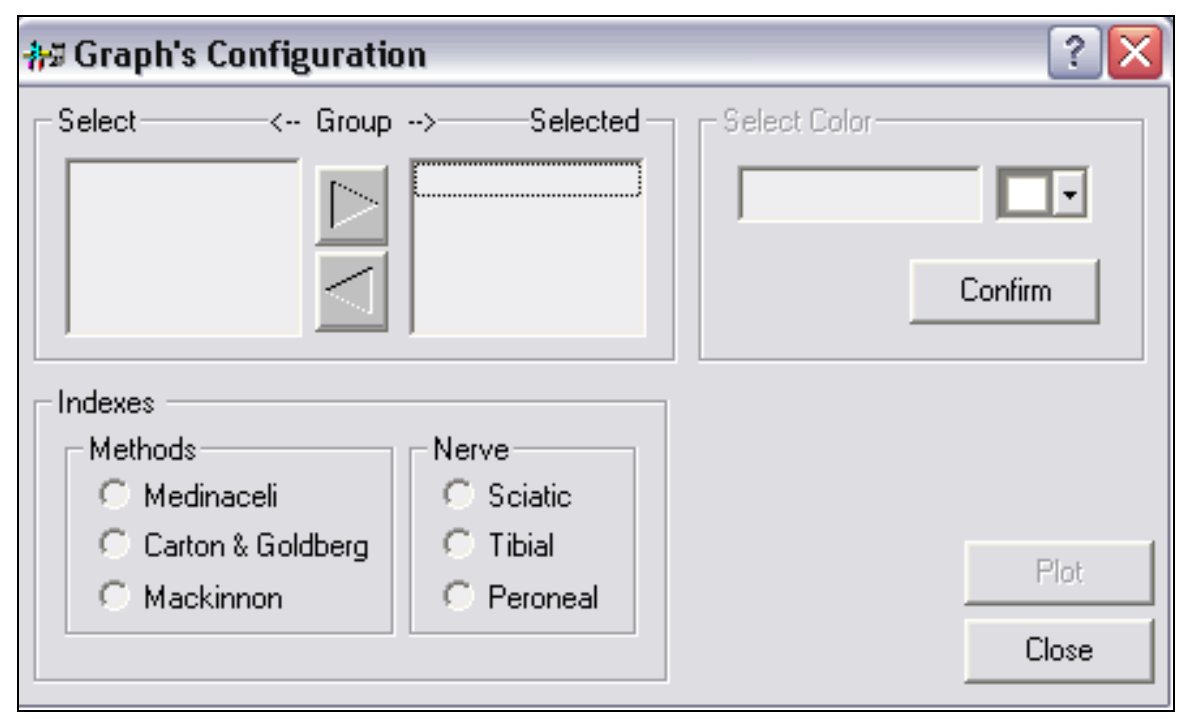

Figura 19: Janela(AFNP) - Configuração de Gráfico

\subsubsection{ESTATÍSTICA}

A janela de Estatística (Statistic) mostra o resultado da janela Graph's Configuration, por meio de um gráfico em relação ao tempo e aos grupos selecionados. O gráfico pode ser visualizado em modo de barras ou de linhas.

Nesta janela o usuário tem a opção de armazenar o gráfico que poderá ser visualizado na janela Historical, por intermédio de um nome de arquivo e de um comentário em relação ao gráfico mostrado. 


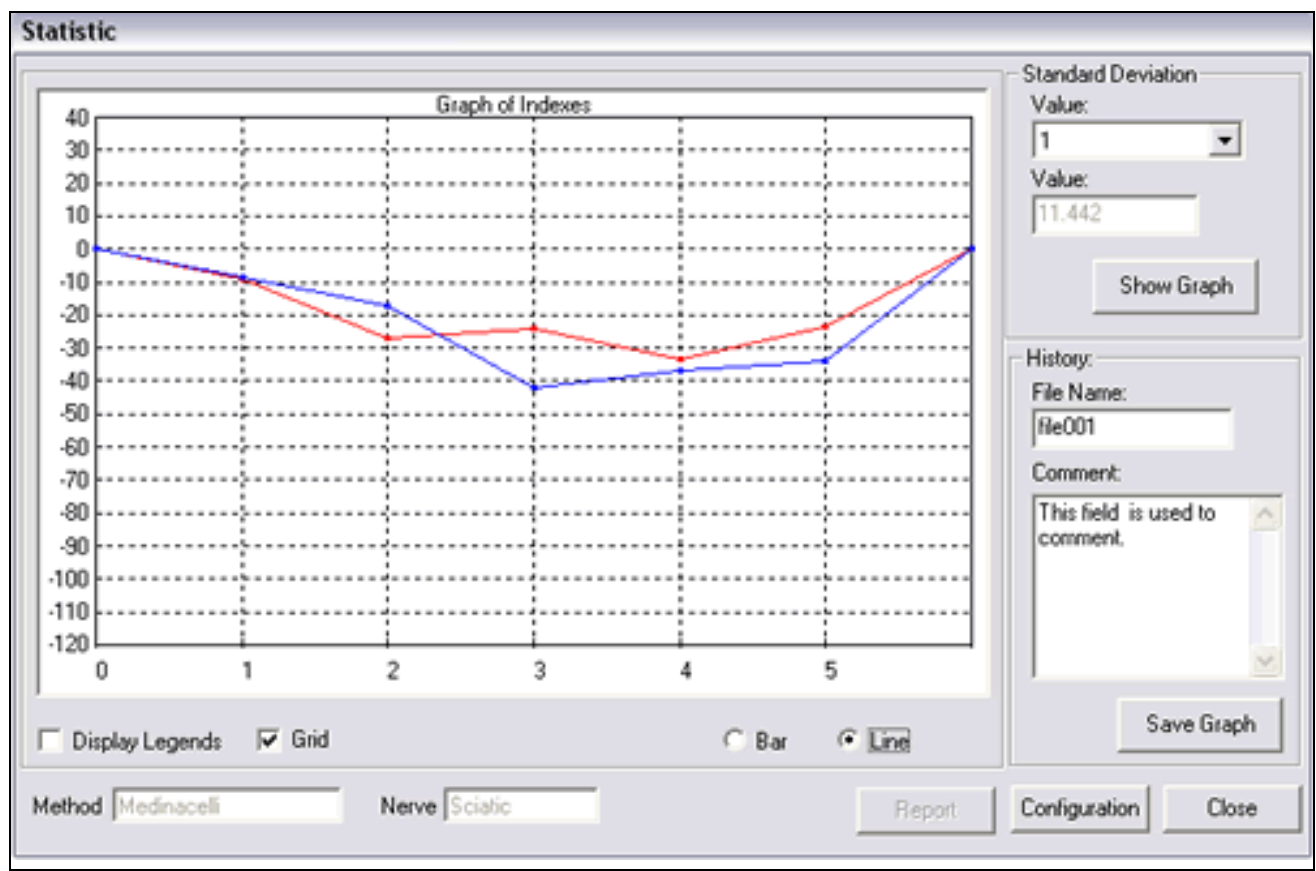

Figura 20: Janela(AFNP) - Estatística

\subsubsection{DESVIO PADRÃO}

A janela Desvio Padrão (Standard Deviation) mostra o gráfico de desviopadrão do resultado obtido da janela Graph’s Configurarion. O usuário também tem a possibilidade de ver o gráfico em modo de barras ou de linha. 


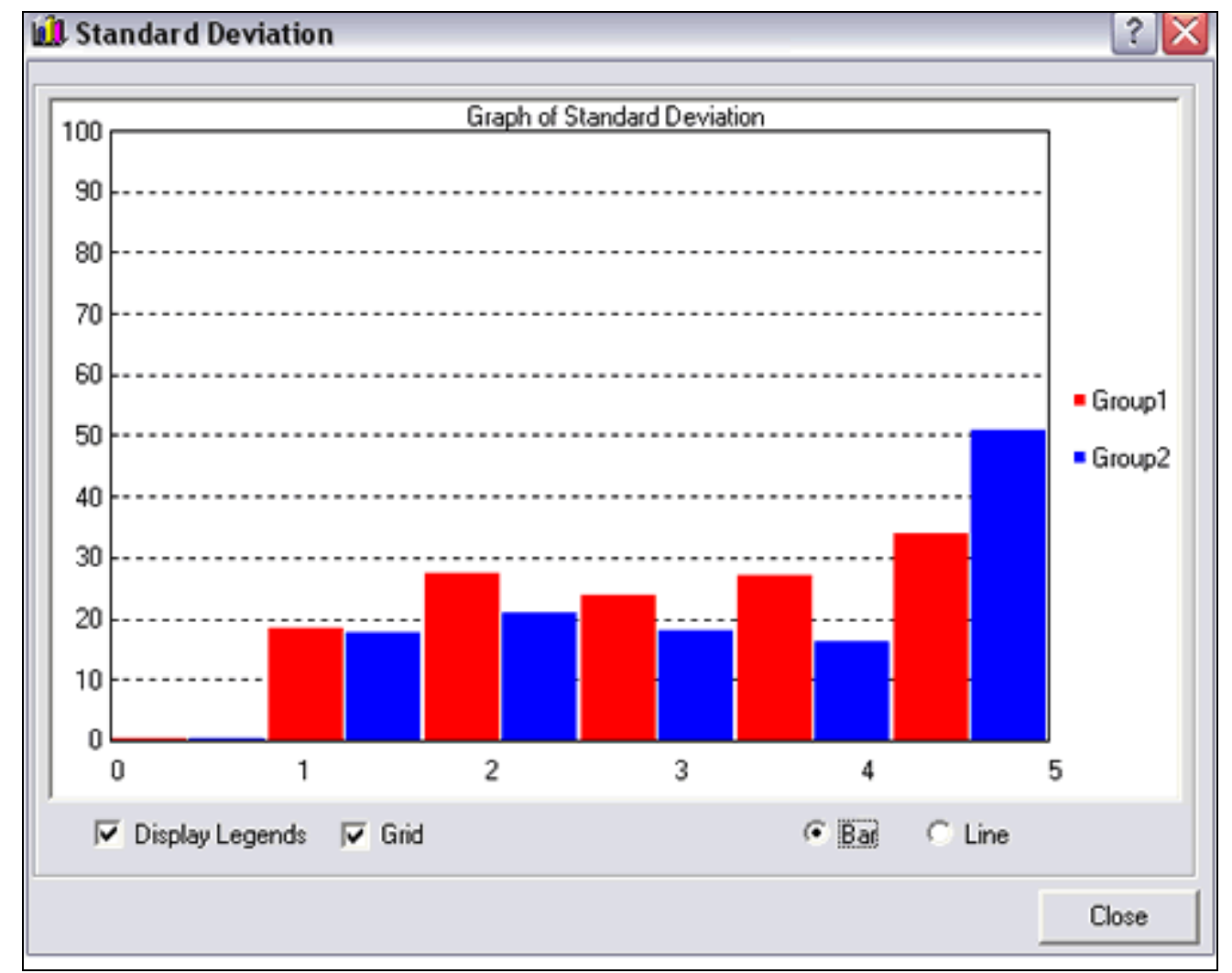

Figura 21: Janela(AFNP) - Desvio Padrão

\subsubsection{HISTÓRICO}

A janela de Histórico (Historical) mostra uma lista de arquivos armazenados pela janela Statistic cujos campos são:

$\checkmark$ Nome do arquivo

$\checkmark$ Método

$\checkmark$ Número do grupo 
$\checkmark$ Desvio-Padrão: valor calculado na janela Statistic e que pode ser visualizado graficamente na janela Standard Deviation.

$\checkmark$ Comentário: conteúdo armazenado pelo usuário sobre o gráfico criado na janela Statistic.

Nesta janela, o usuário tem a possibilidade de pesquisa através dos seguintes itens:

$\checkmark$ Nome do arquivo

$\checkmark$ Método

$\checkmark$ Nervo

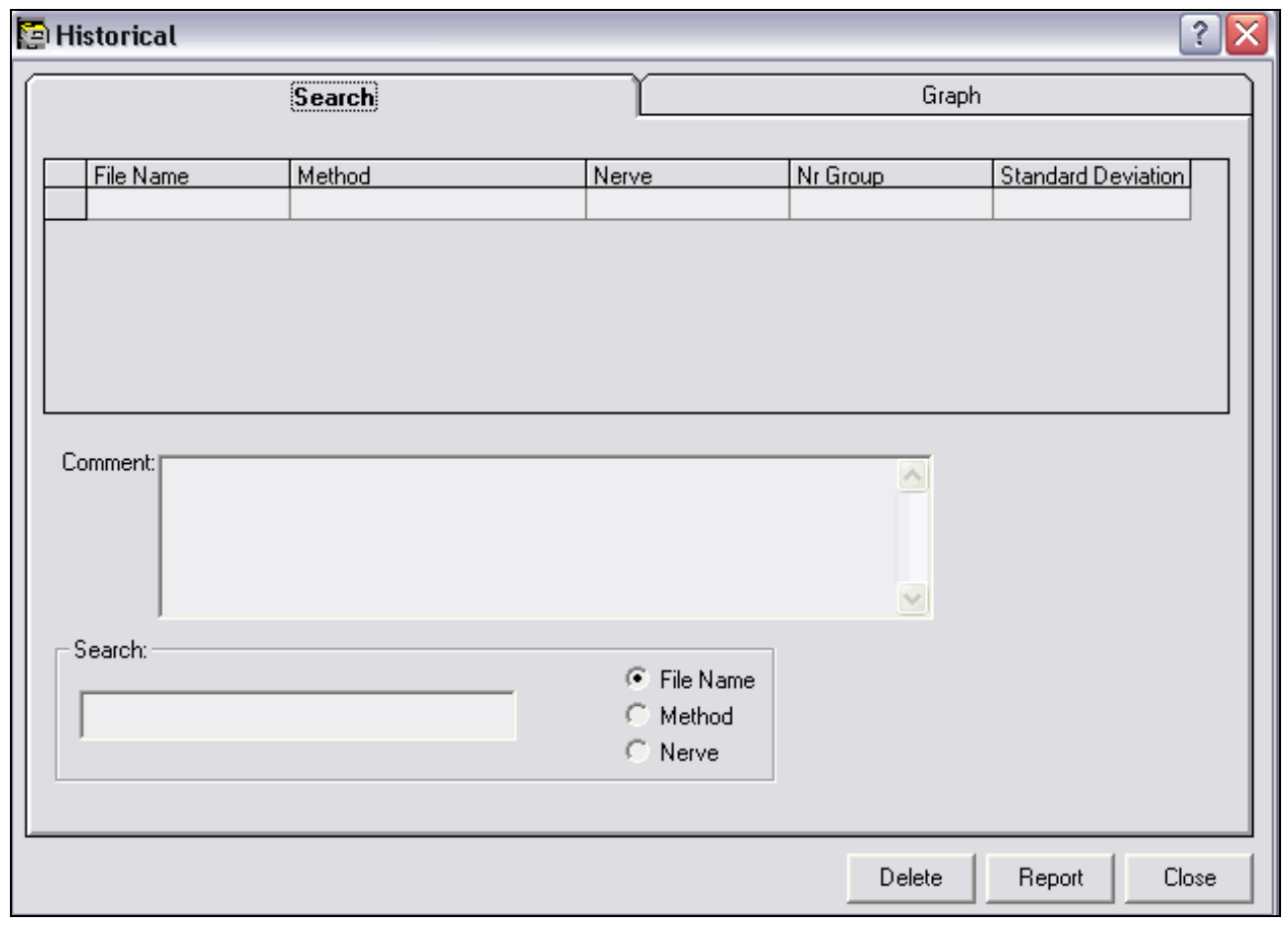

Figura 22: Janela(AFNP) - Aba Pesquisar-Histórico 
E assim quando o usuário selecionar o arquivo desejado que corresponde aos dados do grupo, método ou nervo selecionado, o sistema transfere o foco para a próxima aba Graph, contendo o gráfico que foi armazenado na janela Statistic.

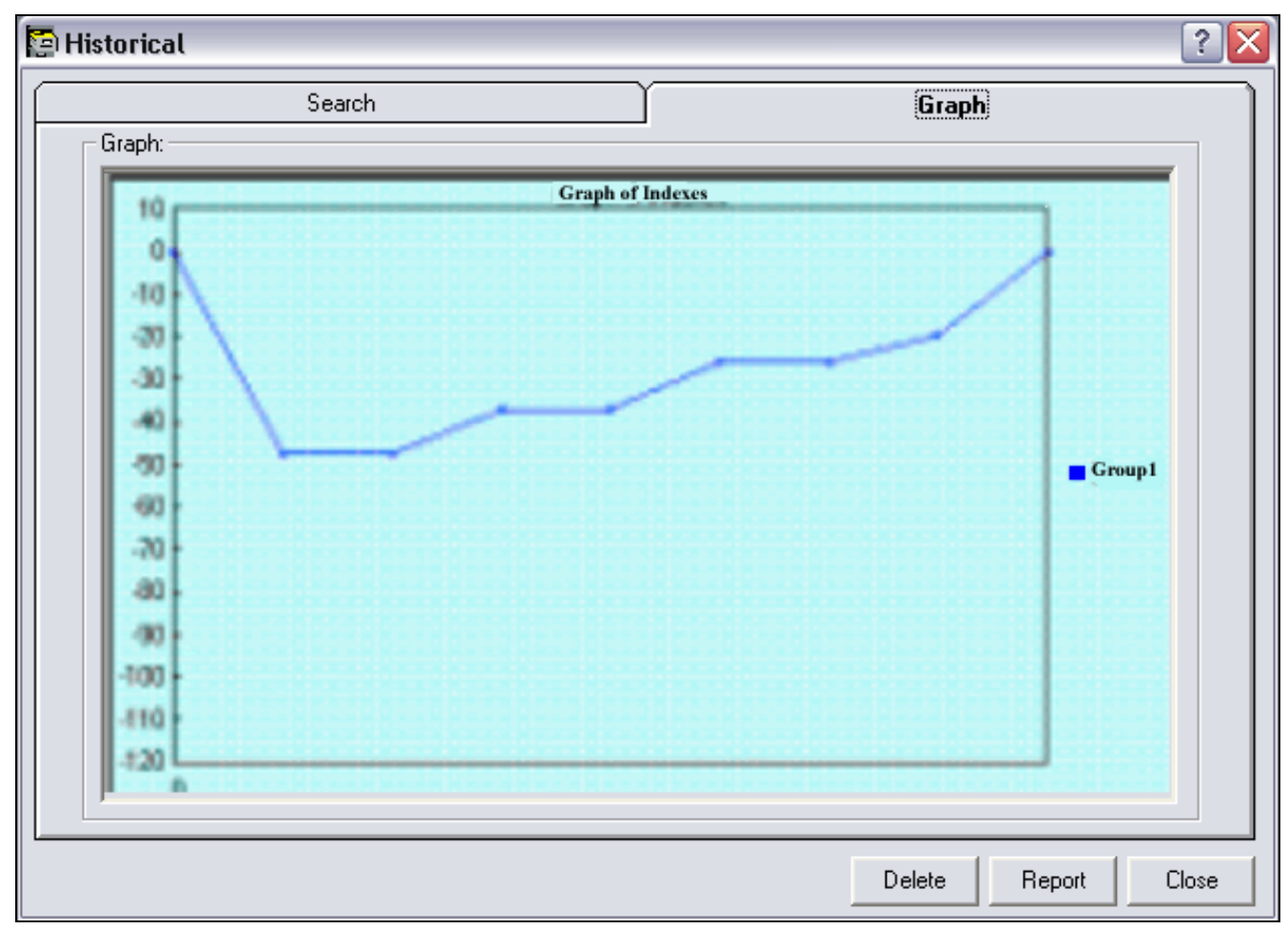

Figura 23: Janela(AFNP) - Aba Gráfico-Histórico

\subsubsection{CHAVE DE VALIDAÇÃO}

O AFNP possui uma chave de validação de uso do sistema. O usuário sem a chave de validação terá as seguintes restrições:

$\checkmark$ Acesso ao menu Graph 
$\checkmark$ Acesso ao menu Historical

$\checkmark$ Relatórios

Para o usuário obter a chave de registro, basta acessar o menu Key e selecionar o submenu Generation, aparecendo assim a janela Generation Key. Clicando no botão Generation será fornecida uma chave de Registro.

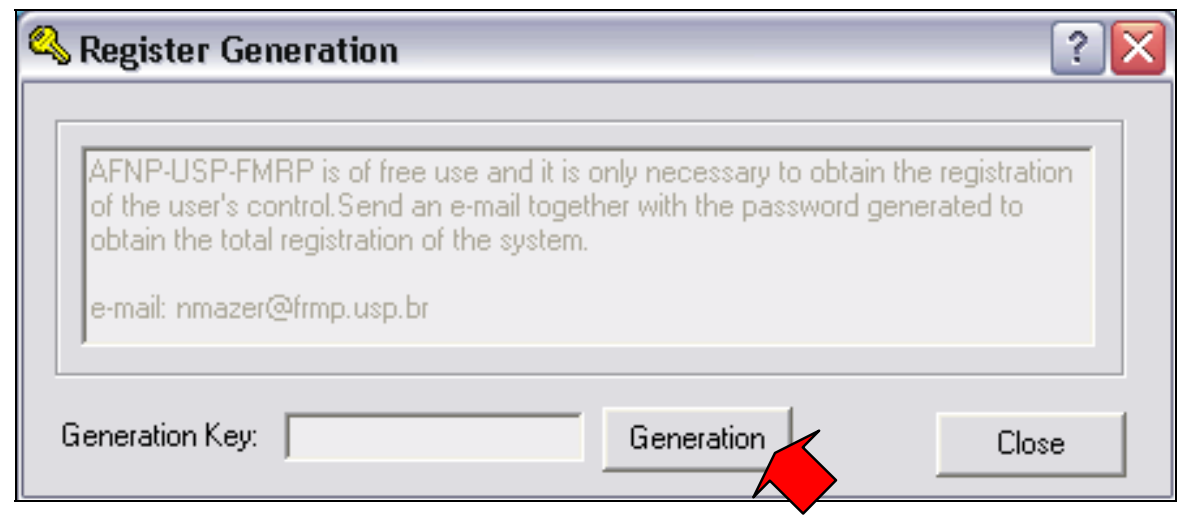

Figura 24: Janela(AFNP) - Geração de Registro

O AFNP é um software livre e é somente necessário este registro para ter um controle dos usuários.

\subsubsection{GERAÇÃO DE REGISTRO}


A Geração de Registro (Register Generation) é um software à parte que, com a chave de registro que foi fornecida pelo software AFNP, gera uma outra chave de registro onde valida a utilização do software.

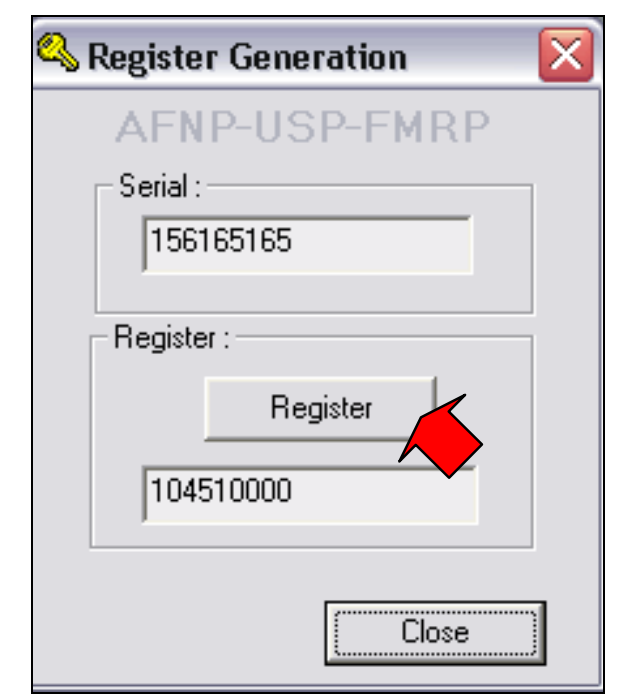

Figura 25: Programa Geração de Registro

\subsubsection{CHAVE DE REGISTRO}

Com a chave de registro fornecida pelo software Register Generation, o usuário acessa novamente o menu Key do sistema AFNP e seleciona o submenu Register, lançando a janela Register Key.

Após ser inserida a chave do registro, o usuário deve inicializar o sistema novamente; fazendo com que o sistema identifique o registro e libere totalmente o sistema para o uso. 


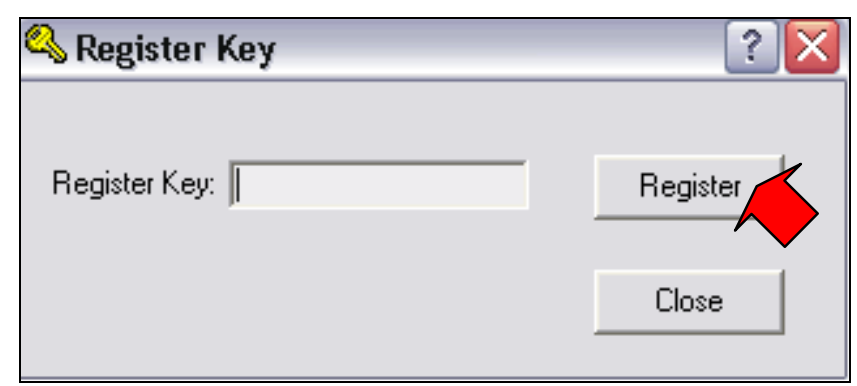

Figura 26: Janela(AFNP) - Chave de Registro

\subsubsection{AJUDA}

Como em todo sistema, o AFNP dispõe de um suporte de ajuda ou Help em dois níveis. Primeiro, o Help Topics, o Help relacionado na apresentação do sistema como um todo, abrangendo assim todas as suas funcionalidades. 


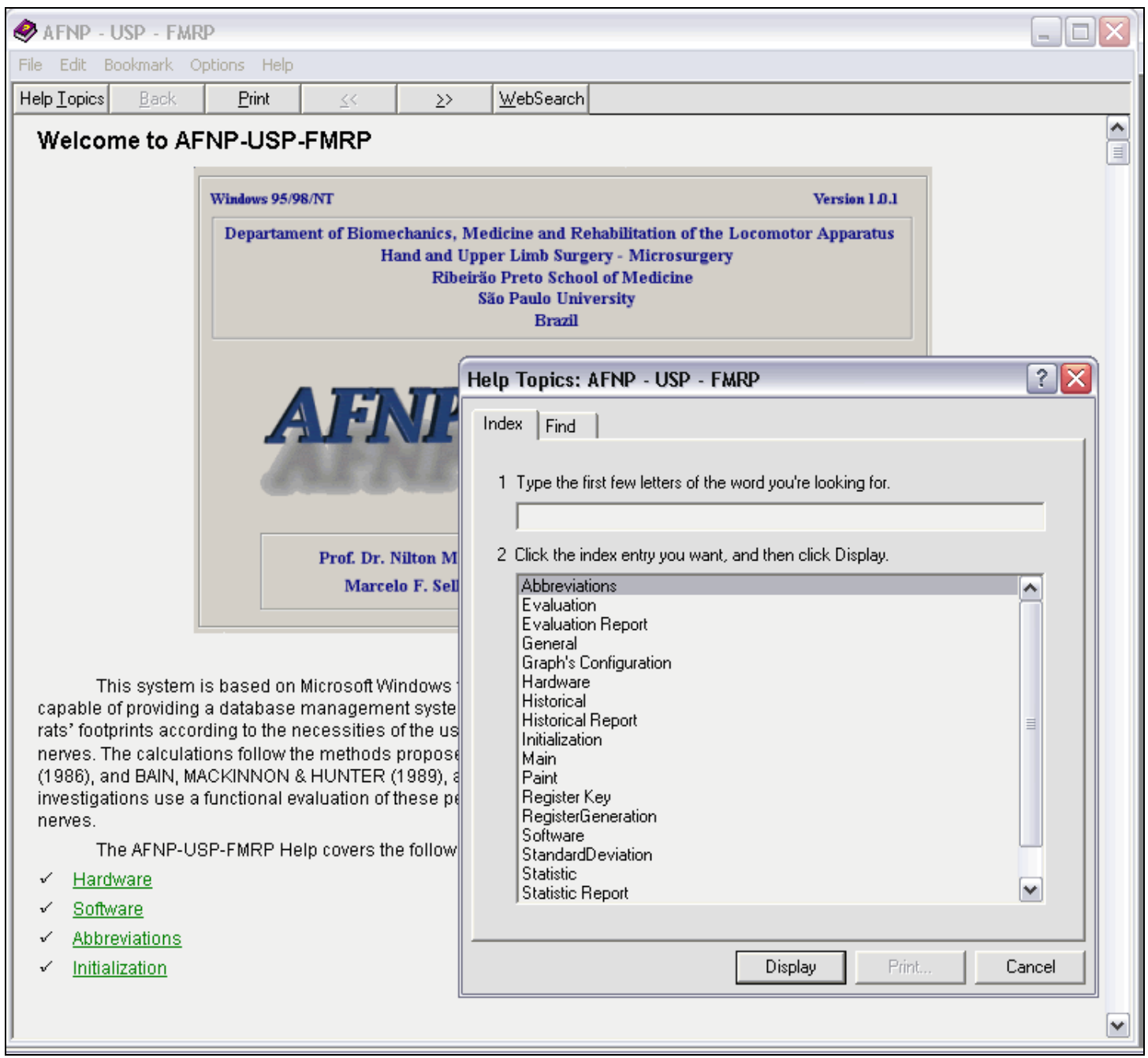

Figura 27: Janela(AFNP) - Tópicos de Ajuda

E o segundo, é o Help Sensitive Context, onde em todas as janelas do sistema possui um botão de ajuda com o sinal “?”. Basta, apenas, o usuário clicar no botão e arrastar o sinal “?”, no qual ele gostará de saber e conhecer do sistema. 


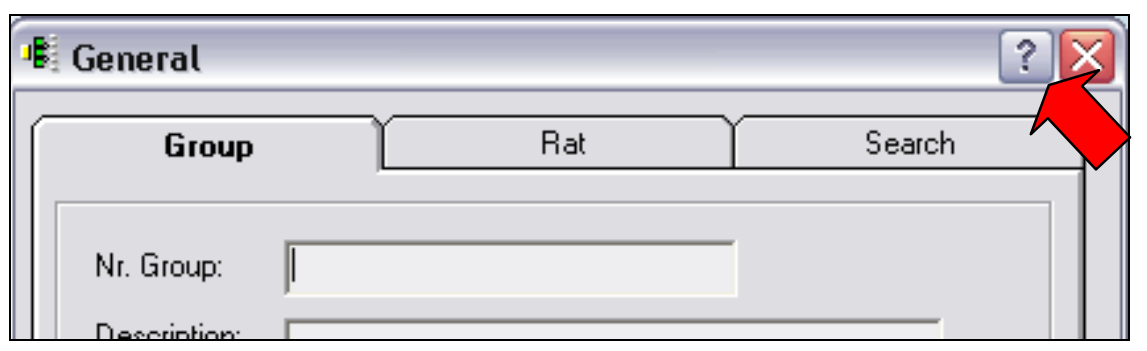

Figura 28: Janela(AFNP) - Botão de Ajuda Sensível ao Contexto

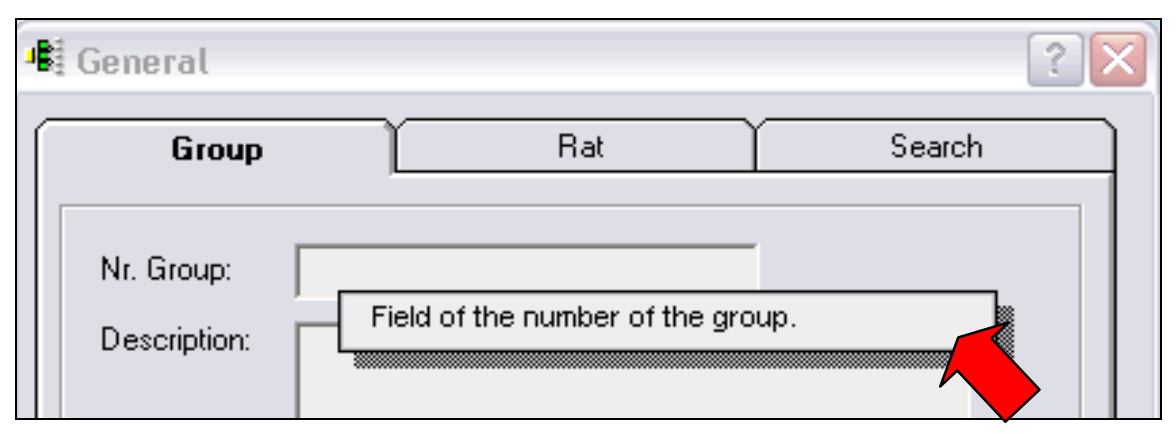

Figura 29: Janela(AFNP) - Ajuda Sensível ao Contexto

\subsection{Utilização do software}

Este software foi testado e fez parte da tese de doutorado da fisioterapeuta Vanessa Vilela Monte Raso. Foi avaliada a reprodutibilidade interpessoal do método de avaliação do Índice Funcional do Ciático (IFC), medido por este programa de computação desenvolvido para este fim. Foram empregados 20 ratos Wistar, cujo nervo isquiático direito era abordado sob anestesia geral e esmagado num segmento de $5 \mathrm{~mm}$ proximal à sua trifurcação com um dispositivo especial, com carga fixa de $5 \mathrm{~kg}$ por 10 minutos. Impressões das pegadas dos animais foram obtidas na fase pré-operatória e, depois, semanalmente, da $1^{\mathrm{a}}$ à $8^{\mathrm{a}}$ semana, em uma pista de marcha. As impressões eram 
digitalizadas, armazenadas e avaliadas pela medida de parâmetros predeterminados, por quatro examinadores, seguindo sempre a mesma seqüência de marcação dos parâmetros. Os resultados conforme podem ser visto no gráfico 2 e na tabela 3 foram submetidos à análise estatística que mostrou haver um alto índice de correlação interpessoal na $3^{\mathrm{a}}, 4^{\mathrm{a}}$, $5^{\mathrm{a}}, 7^{\mathrm{a}}$ e $8^{\mathrm{a}}$ semanas (igual ou maior que 0,82 ), com queda casual na $6^{\mathrm{a}}$ semana, mas sem diferença significante com as demais $(\mathrm{p}<0,01)$. Na $1^{\mathrm{a}}$ e $2^{\mathrm{a}}$ semanas, o índice de correlação foi próximo de zero, mostrando a pouca reprodutibilidade do método nesse período, em que a variabilidade entre os animais não diferiu da variabilidade entre os examinadores ( $\mathrm{p}=0,24$ e 0,32 , respectivamente), devido à pouca definição das impressões das pegadas. A autora concluiu que o método de avaliação funcional experimental pelo Índice Funcional do Ciático, em ratos, é plenamente reprodutível e confiável, quando aplicado após a segunda semana da produção de uma lesão por esmagamento do nervo e confirmou a suspeita de que a má qualidade das pegadas das duas primeiras semanas praticamente tornava impossível uma avaliação adequada. Considerando a rapidez da regeneração do nervo isquiático de ratos, a mesma conclusão pode ser aplicada a outros tipos de lesão, como a secção e sutura ou adesão do nervo, interposição de enxertos e outras, provavelmente com a extensão do período de irreprodutibilidade inicial. 


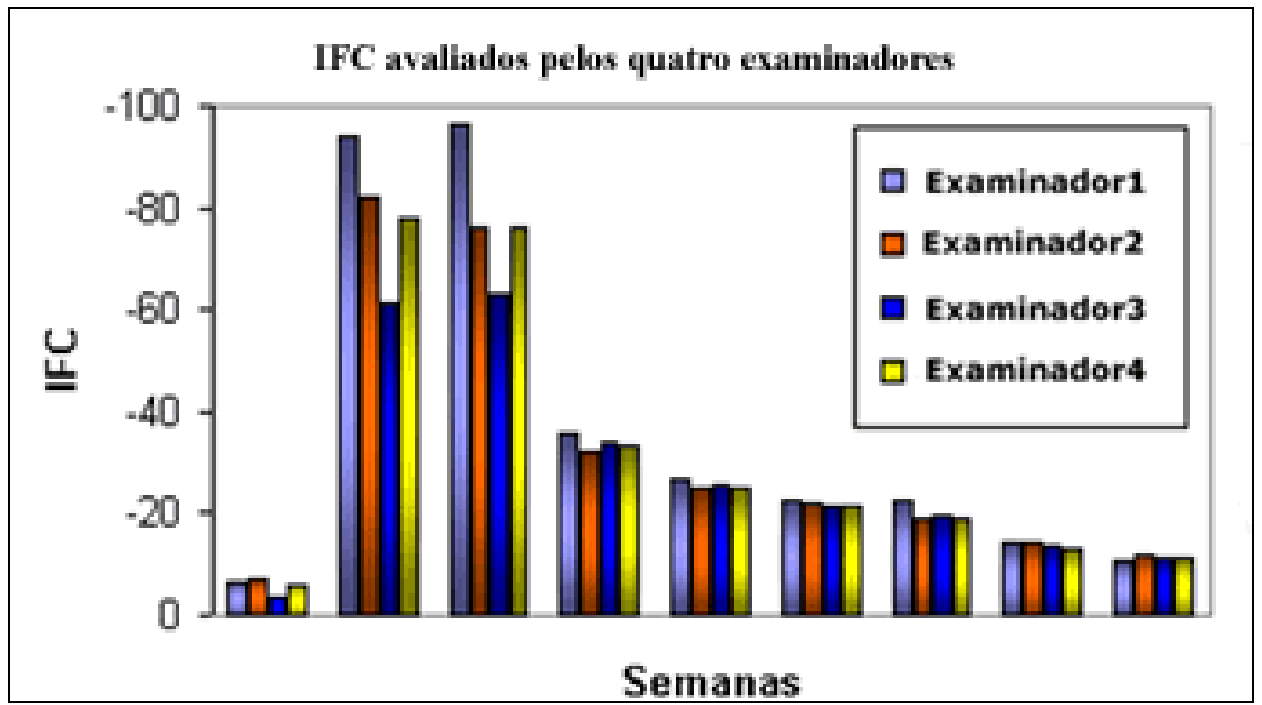

Gráfico 2: Avaliação dos quatro examinadores

\begin{tabular}{|c|c|c|c|c|c|c|}
\hline \multirow{5}{*}{$\begin{array}{r}\text { Pré-Operatória } \\
1^{\circ} \text { Semana }\end{array}$} & & $\begin{array}{l}\mathbf{E} \\
\mathbf{x} \\
\mathbf{a} \\
\mathbf{m} \\
\mathbf{i} \\
\mathbf{n} \\
\mathbf{a} \\
\mathbf{d} \\
\mathbf{0} \\
\mathbf{r}\end{array}$ & $\begin{array}{l}\mathbf{E} \\
\mathbf{x} \\
\mathbf{a} \\
\mathbf{m} \\
\mathbf{i} \\
\mathbf{n} \\
\mathbf{a} \\
\mathbf{d} \\
\mathbf{0} \\
\mathbf{r}\end{array}$ & $\begin{array}{l}\mathbf{E} \\
\mathbf{x} \\
\mathbf{a} \\
\mathbf{m} \\
\mathbf{i} \\
\mathbf{n} \\
\mathbf{a} \\
\mathbf{d} \\
\mathbf{0} \\
\mathbf{r}\end{array}$ & \multicolumn{2}{|l|}{$\begin{array}{l}\mathbf{E} \\
\mathbf{x} \\
\mathbf{a} \\
\mathbf{m} \\
\mathbf{i} \\
\mathbf{n} \\
\mathbf{a} \\
\mathbf{d} \\
\mathbf{0} \\
\mathbf{r} \\
\end{array}$} \\
\hline & & 1 & 2 & 3 & 4 & \\
\hline & & A & B & C & D & E \\
\hline & 1 & $-6,487$ & $-6,847$ & $-3,451$ & $-6,079$ & \\
\hline & 2 & $-93,911$ & $-82,241$ & $-61,552$ & $-77,823$ & \\
\hline $2^{\circ}$ Semana & 3 & $-96,226$ & $-76,219$ & $-62,902$ & $-76,233$ & \\
\hline $3^{\circ}$ Semana & 4 & $-35,478$ & $-31,893$ & $-34,144$ & $-33,349$ & \\
\hline $4^{\circ}$ Semana & 5 & $-26,686$ & $-24,884$ & $-25,53$ & $-24,898$ & \\
\hline $5^{\circ}$ Semana & 6 & $-22,407$ & $-22,227$ & $-21,22$ & $-21,606$ & \\
\hline $6^{\circ}$ Semana & 7 & $-22,8$ & $-19,192$ & $-19,497$ & $-19,316$ & \\
\hline $7^{\circ}$ Semana & 8 & $-14,059$ & $-14,365$ & $-13,707$ & $-13,091$ & \\
\hline $8^{\circ}$ Semana & 9 & $-10,948$ & $-11,868$ & $-11,539$ & $-11,5$ & \\
\hline & 10 & & & & & \\
\hline
\end{tabular}

Figura 30: Valores obtidos da Avaliação 


\subsection{Pôster}

O AFNP foi apresentado no $23^{\circ}$ Congresso Brasileiro de Cirurgia de Mão, VII

Congresso Brasileiro de Reabilitação da Mão e II Jornada Luso-Franco-Brasileira de Terapia da Mão em 2003, como trabalho científico em forma de pôster. 


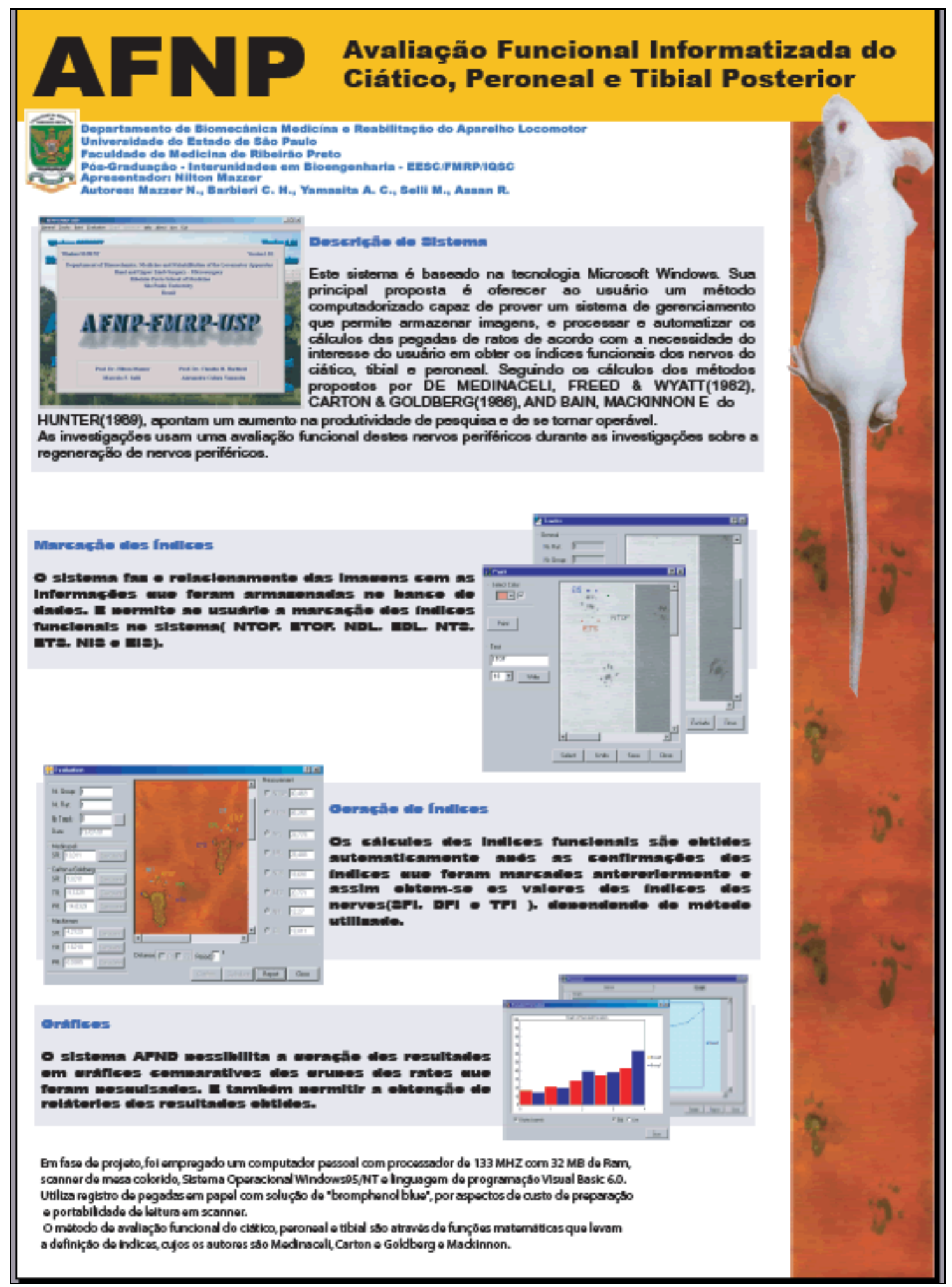

Figura 31: Pôster AFNP 


\title{
6 Discussão
}

\begin{abstract}
A regeneração nervosa periférica observada em estudos experimentais apresenta aspectos controversos, porque nem sempre é possível estabelecer uma correlação clara entre os resultados obtidos pelas diferentes metodologias empregadas, particularmente aqueles obtidos em estudos diferentes, conduzidos por autores diferentes. A maioria dos estudos sobre a regeneração dos nervos periféricos emprega métodos histomorfométricos e eletrofisiológicos, os quais, embora essenciais, não adiantam nenhuma informação sobre a recuperação funcional correspondente. (Monte Raso VV; Barbieri CH; Mazzer N; Fasan VS, 2005).
\end{abstract}

A principal motivação da informática na saúde é o aumento progressivo no aumento da quantidade de dados, informações e conhecimento que o profissional da saúde deve utilizar para exercer adequadamente a sua profissão (CIS-EPM). Entretanto, mesmo com dados adequados e conhecimento pertinente, é necessário que se faça o uso de uma abordagem inteligente na solução dos problemas. E (Shortliffe, 1990) em seu livro Medical Informatics, define os sistemas de apoio à decisão (SAD) em Medicina, como todo software que auxilie os médicos na solução de problemas. Portanto, o AFNP é mais um dos resultados em que pode ser preceptivo que a informática tem um impacto positivo no aumento da produtividade e no apoio aos médicos no processo diário de tomada de decisão, com base em conhecimento especializado. 
Segundo uma avaliação que os profissionais de Medicina fazem do impacto dos avanços no uso de computadores e da Internet na qualidade dos serviços médicos do país (impacto positivo, negativo ou neutro), é um indicador claro da relação entre tais laboratórios e os médicos. O diagrama abaixo mostra como se distribui tal relação entre os 465 profissionais abordados aleatoriamente nas ruas e nas diversas instituições de saúde.

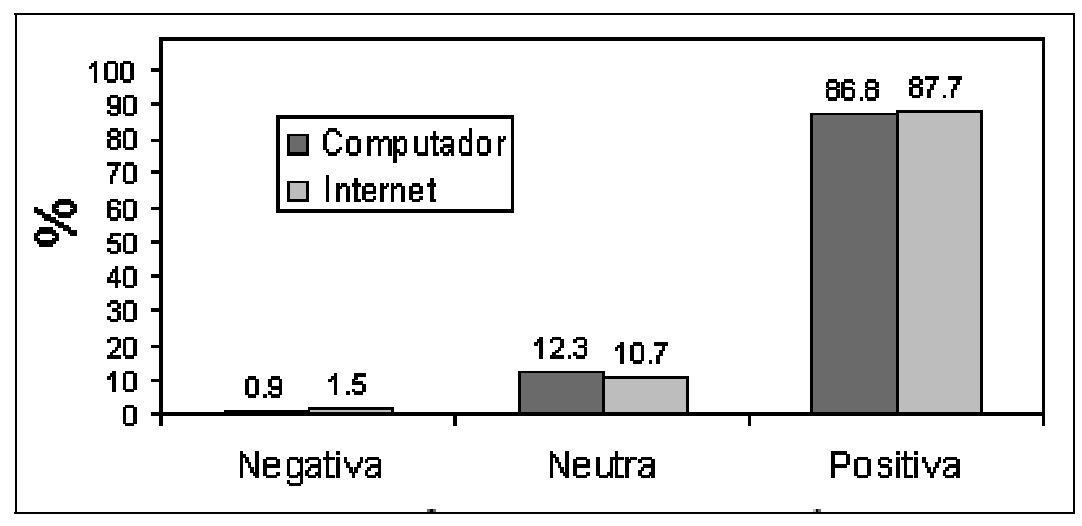

Gráfico 3: Evolução da Informática

Como se pode ver, a esmagadora maioria dos médicos entrevistados considera que tanto os computadores quanto a Internet representam um impacto positivo na qualidade dos serviços de saúde do país, com uma pequena fração considerando esse efeito como neutro e menos de uma dezena de indivíduos identificando tal influência como negativa. Em suma, tem-se a clara predominância de uma percepção favorável.(IATROS - Vade Mecum Consultoria (2002/2003)). 
Atento às funcionalidades exigidas na fase de análise do projeto e assim pela opção de utilizar como hardware, o computador pessoal PC/AT foi de fácil aquisição e não necessitando de nenhum tipo de treinamento para com os usuários. No sistema operacional, foi Microsoft Windows ${ }^{\mathrm{TM}}$ seguindo neste mesmo parâmetro de escolha. E conseguindo, assim, uma portabilidade no uso da ferramenta de software nas várias versões do sistema operacional que existe no mercado. A decisão foi tomada com base, também, na análise da relação custo/benefício, uma vez que as tecnologias selecionadas atendem satisfatoriamente às necessidades descritas, com baixos custos.

A flexibilidade foi uma meta importante imposta neste projeto. O software fornece a possibilidade de vários grupos serem analisados ao mesmo tempo e serem comparados, segundo os métodos dos nervos periféricos estudados. Outra forma notada da flexibilidade é no tocante ao uso de mais de um usuário poder trabalhar com uma mesma instalação do sistema em um mesmo computador. Bastando, apenas, ter em mãos os dados armazenados em um arquivo do aplicativo Microsoft Access e das pegadas onde foram digitalizadas em arquivos no formato de imagens.

A escolha do banco de dados Microsoft Access foi para permitir excluir a necessidade do sistema ou do usuário necessitar da instalação de uma base de dados ou de um mecanismo de um banco de dados para a persistência dos dados. E, além disso, para a utilização do sistema não existe a necessidade do software Microsoft Access estar instalado no computador do pesquisador. E também deve ser ressaltada a facilidade na transferência das informações das análises contidas no banco de dados de um 
computador para o outro, bastando apenas o usuário copiar o arquivo “usp.mdb” contido no sistema para o outro sistema instalado em outro computador, juntamente com as imagens das respectivas análises.

Do ponto de vista da vida do software, após terminar a etapa de Transição com os pesquisadores é concluído assim, um ciclo do processo Iterativo e Incremental adotado como método de desenvolvimento do sistema. Para iniciar um novo ciclo é necessário fazer um novo levantamento de requisitos ou de melhorias a serem feitas no software, que podem ser passadas pelos usuários ou por quem esteja coordenando o projeto (feedback). Esta etapa é muito importante para o software, pois com as novas melhorias sugeridas, juntamente com a inserção dos novos requisitos sugerido para o próximo ciclo do processo, indicará o sucesso e a usabilidade do sistema.

Vários trabalhos já foram publicados sobre análise dos nervos periféricos justificando ou com o auxílio dos meios computacionais:

o Correlation between functional index and morphometry to evaluate recovery of the rat sciatic nerve following crush injury: experimental study. (Oliveira, E.F.; Mazzer, N.; Barbieri, C.H.; Chimelli, L.M.C.; Selli, M. - J. Reconstr. Microsurg., 17(1): 69-75, 2001 (Doc. 727)).

o Directly applied low intensity direct electric current enhances peripheral nerve regeneration in rats. Mendonça, A.C.; 
Barbieri, C.H.; Mazzer, N. - J. of Neurosci. Methods, 129(2): 183-190, 2003 (Doc. 729).

o The use of a muscle graft to repair a segmentary nerve defect. An experimental study using the sciatic nerve of rats as model. Oliveira, E.F.; Mazzer, N.; Barbieri, C.H.; DelBel, E.A. - J. of Neurosci. Methods, 133(1-2): 19-26, 2004 (Doc. 730).

o The end-to-side peripheral nerve repair. Functional and morphometric study using the peroneal nerve of rats. De Sá, J.M.R.; Mazzer, N.; Barbieri, C.H.; Barreira, A.A. - J. of Neurosci. Methods, 136(1): 45-53, 2004 (Doc. 731).

o Can therapeutic ultrasound influence the regeneration of peripheral nerves? Monte-Raso, V.V.; Barbieri, C.H.; Mazzer, N.; Fasan, V.S. - J. of Neurosci. Methods, 142(2): 185-192, 2005 (Doc. 732).

o Índice funcional do ciático nas lesões por esmagamento do nervo ciático de ratos. Avaliação da reprodutibilidade do método entre examinadores. Monte-Raso, V.V.; Barbieri, C.H.; Mazzer, N. - Acta. Ortop. Bras., 14(3): 133-136, 2006 (Doc. ).

- Os efeitos do ultra-som terapêutico nas lesões por esmagamento do nervo ciático de ratos: análise funcional da marcha. Monte-Raso, V.V; Barbieri, C.H.; Mazzer, N.; Fazan, 
V.P.S. - Revista Brasileira de Fisioterapia, 10(1): 113-119, 2006 (Doc.).

Uma das melhorias a serem inseridas no AFNP será na captação das pegadas dos ratos para otimizar em relação ao fator tempo, pois muitas pegadas são desperdiçadas pelos pesquisadores devido ao problema da difusão radial nas pegadas. Há alguns trabalhos que já foram realizados como o de (Westerga; Gramsbergen, 1990) que introduziu o uso de um espelho a fim de obter mais de uma visão da pegada e de (Walker, 1994), a técnica de captura por meio de vídeo. 


\section{Conclusões}

O AFNP é um software flexível porque o pesquisador não se limita em uma instalação do software em um local. Ou também uma instalação do software não se destina a apenas a um só pesquisador.

A facilidade do uso do software devido ser intuitivo e explicativo foi realmente encontrada desde a instalação onde o pesquisador não tem a necessidade de nenhuma pré-instalação de outros softwares, da disposição da escolha do idioma e em todas as fases da análise da pesquisa, o auxílio em modos de ajuda em relação ao contexto ou ao do processo informatizado.

A utilização desse software proporciona a possilibidade de realizar uma uniformidade dos métodos empregados nas pesquisas.

Permite acessos às informações armazenadas dos diferentes métodos de pesquisas que foram armazenadas no histórico da ferramenta, podendo assim ser utilizado em futuros estudo. 


\section{Referências Bibliográficas}

BAIN, J.R.; MACKINNON, S. E.; HUNTER, D. A. (1989) - Functional evaluation of complete sciatic, peroneal and posterior tibial nerve lesions in the rat. Plast Reconst Surg., 83: 129-138.

BERGERON, B. (2002). Bioinformatics computing. Upper Saddle River, NJ: Prentice Hall/Professional Technical Reference.

BORGES, D.R.; ROTHSCHILD, H.A. (2001). Atualização terapêutica: manual prático de diagnóstico e tratamento. 20. ed. São Paulo: Artes Médicas, p. 1348-1351.

BRIDGE, P.M.; BALL, D.J.; MACKINNON, S.E.; NAKAOI, Y.; BRANDT, K.; HUNTER, D.A.; HERTL, C. (1994). Nerve crush injuries: a model for axonotmesis. Experimental Neurology, Orlando, v.127, p.284-290.

CARTON, J. M. \& GOLDBERG, N.H. (1986) - Quantitating Integrated muscle function following reinvervation. Surgical Forum, Chicago, v.37, p. 611-612.

BROWN, C.J. ET AL (1991- Inter and intraobserver reliability of walking-track analysis used to assess sciatic nerve function in rats. Microsurgery, Hoboken, v. 12, p.76-79. 
CURRIER, D. P.; GREATHOUSE,D; SWIFT, T. (1978) - Sensory nerve conduction: effect of ultrasound. Arch Phts Med Rehabil, 1978, v.59, p.181 - 185.

DELLON A.L.; M.D., \& S.E. MACKINNON, M.D.(1989). Sciatic nerve regeneration in the rat validity of walking track assessment in the presence of chronic contractures. Microsurgery, Hoboken, v. 10, p.220-225.

DE MEDINACELI, L.; FREED, W.J.; WYATT, R.J. (1982) - An Index of the functional condition of rat sciatic nerve based on measurements made from walking Tracks. Exp. Neural, 1982, v.77, p.634-643.

GIBAS, C.; JAMBECK, P. (2001) - Developing Bioinformatics Computer Skills - $1^{\circ}$ Edição - O’Reilly

KIRTLAND M. (2000). Projetando Soluções baseadas em componentes - $2^{\circ}$ Edição - Série Microsoft Programming - Ed. Campus.

KORTH, H. F. e SILBERSCHATZ A. (1993) - Sistema de Banco de Dados, São Paulo: Makron.

LOWNDON, I.M.R.; SEABER, A.V.; URBANIAK, J.R.(1988). An improved method of recording rat tracks for measurement of the sciatic functional index of de Medinaceli. Journal Neuroscience Methods, Amsterdam, v.24, p. 279-281.

LUDEMIR, J. (2000). Microsoft Visual Basic 6.0 Expert SEM LIMITES - Microsoft Press, São Paulo: Ed. Berkeley.

MACDONALD, M. (1999). Exam CRAM - MCSD Visual Basic 6 Desktop - Exam 70-176 , U.S.: Coriolis Group Books 
MARQUES FILHO, O.;VIEIRA NETO, H. (1999). Processamento digital de imagens. São Paulo : Brasport.

MURRAY, C. (1998) - Object-Oriented Project Management with UML, New York - Wiley Computer Publishing.

PAUL R. REED, JR(2000) - Desenvolvendo Aplicativos com Visual Basic e UML São Paulo: Ed. Makron Books

ROD STEPHENS (1999) - Visual Basic Graphics Programming - Hands-On Applications and Advanced Color Development - Second Edition - Ed. Wiley

ROGER S. PRESSMAN (1997) - Engenharia de Software - $3^{\circ}$ Edição - Ed. Makron Books.

TERRY QUATRANI (2001) - Modelagem Visual com Rational Rose 2000 e UML Ed. Ciência Moderna.

THE MANDELBROT SET, INTERNATIONAL, LTD. (1998) - Advanced Microsoft Visual Basic 6.0, 2nd Edition - Redmond, Wash. - Microsoft Press.

SELLI, M. F. (1998) - Desenvolvimento de um método computadorizado para avaliação funcional das lesões de nervos periféricos através da análise da marcha modelo experimental em ratos. 60 f. Dissertação (Mestrado) - Interunidades Bioengenharia, Faculdade de Medicina de Ribeirão Preto e Escola de Engenharia de São Carlos, Universidade de São Paulo, Ribeirão Preto, 1998.

SIGULEM D. (1997) - Um novo paradigma de aprendizado na prática médica da UNIFESP/EPM. 177 f. Tese (Livre Docência)- Escola Paulista de Medicina, Universidade Federal de São Paulo, São Paulo, 1997. 
SOCIEDADE BRASILEIRA DE ANATOMIA. TERMINILOGIA ANATÔMICA. São Paulo - Manole; 2001 p.169.

VAREJÃO, A. et al (2001) - Functional evaluation of peripheral nerve regeneration in the rat: walking track analysis. Journal of Neuroscience Methods, Amsterdam, v.108, p. 1 - 9 .

VAREJÃO, A. et al (2001) - Functional assessment of peripheral nerve recovery in the rat: gait kinematics. Microsurgery, Hoboken, v. 21, p. 383-388. 